\title{
Image Analysis for Trabecular Bone Properties on Cone-Beam CT Data
}

\author{
Eva Klintström
}

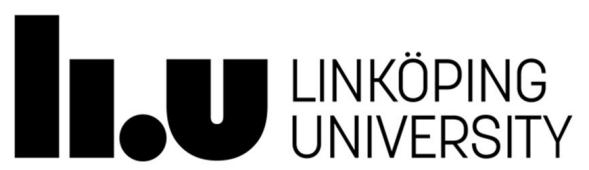

Department of Medical and Health Sciences

Linköping University, Sweden

Linköping 2017 
(c) Eva Klintström, 2017

Cover: Design Benjamin Klintström. Front page photo from the Norrköping Light Festival, 25 December 2015

This work has been conducted in collaboration with the Center for Medical Image Science and Visualization (CMIV) at Linköping University, Sweden. CMIV is acknowledged for provision of financial support and access to leading edge research infrastructure

Published articles have been reprinted with the permission of the copyright holders.

Printed in Sweden by LiU-Tryck, Linköping, Sweden, 2017

ISBN 978-91-7685-434-1

ISSN $0345-0082$ 
To Gotland,

my favourite place on earth

Visst skudd de vare trist skudd de var um Gotland inte fanns

Man kan ha svikt ei bainrangle yvarallt, ei alle baini ei kruppen - u ei käpen mä. 
Main supervisor

\section{Örjan Smedby}

School of Technology and Health, KTH Royal Institute of Technology,

Stockholm, Sweden

and

Department of Medical and Health

Sciences, Division of Radiology Sciences, Linköping University

Linköping, Sweden

\section{Supervisors}

\section{Rodrigo Moreno}

School of Technology and Health, KTH Royal Institute of Technology, Stockholm, Sweden

\section{Torkel Brismar}

Department of Clinical Science, Intervention and Technology at Karolinska Institutet and

Department of Radiology, Karolinska University Hospital, Huddinge, Stockholm, Sweden
Faculty opponent

\section{Dan Mellström}

Geriatric Medicine, Department of Internal Medicine and Clinical Nutrition, University of Gothenburg, Gothenburg Sweden and

Centre for Bone and Arthritis Research at the Sahlgrenska Academy, University of Gothenburg, Gothenburg Sweden

\section{Committee board}

\section{Jan Engvall}

Department of Medical and Health

Sciences, Division of Cardiovascular medicine, Linköping University, Linköping, Sweden

\section{Mats Geijer}

Department of Radiology, Faculty of Medicine and Health, Örebro University, Örebro, Sweden and

Department of Clinical Sciences, Lund University, Lund, Sweden

\author{
Andreas Thor \\ Department of Surgical Sciences, \\ Plastic \& Oral Maxillofacial Surgery, \\ Uppsala University, \\ Uppsala, Sweden
}

Alternative member of the Committee Board

\section{Ola Wahlström}

Department of Clinical and Experimental Medicine, Division of Surgery, Orthopedics and Oncology, Linköping University, Linköping, Sweden 


\section{Content}

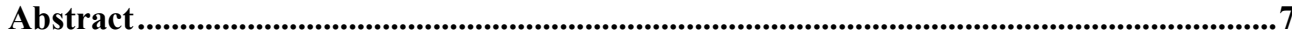

Populärvetenskaplig sammanfattning...............................................................................................9

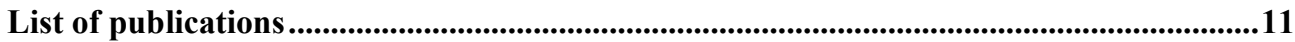

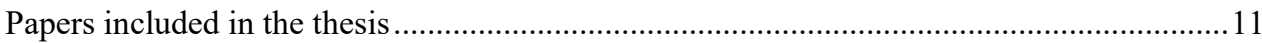

Papers published as part of the project, not included in the thesis ........................................ 11

Scientific paper related to, but not part of, the project........................................................... 11

Conference papers published as part of the project ............................................................. 12

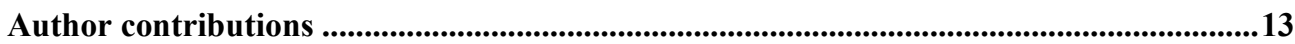

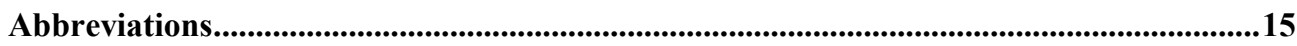

Acknowledgements........................................................................................................................................17

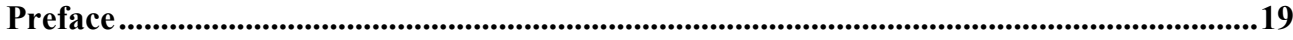

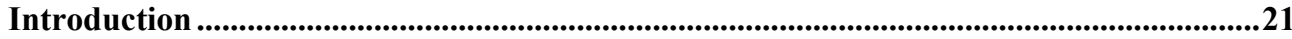

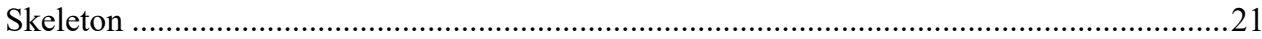

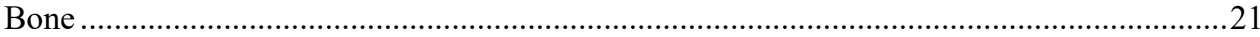

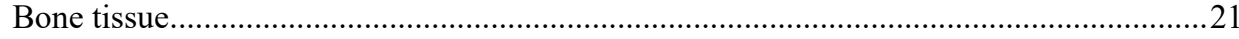

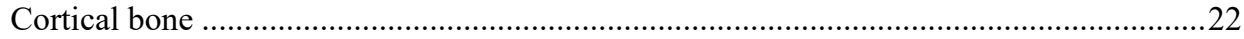

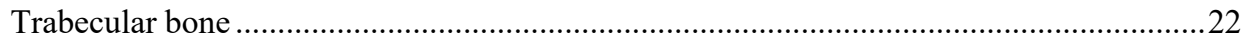

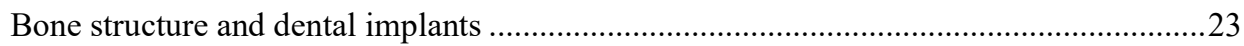

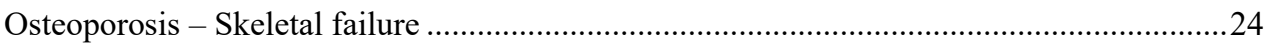

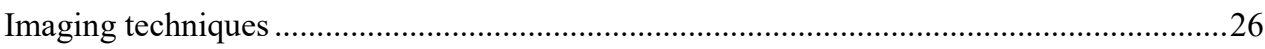

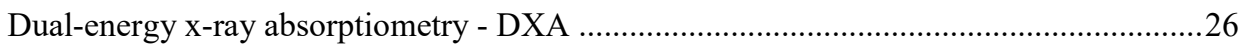

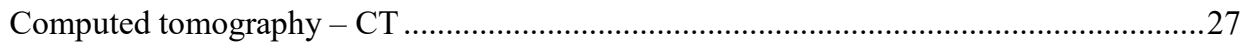

High- resolution peripheral quantitative computed tomography - HR-pQCT ...................29

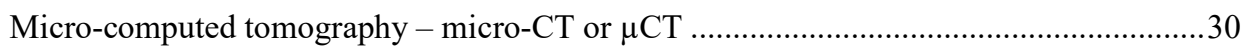

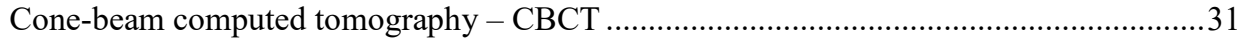

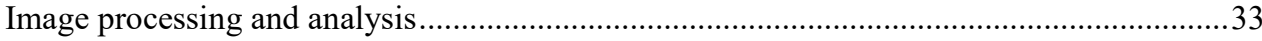

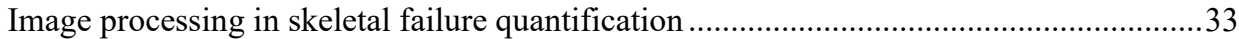

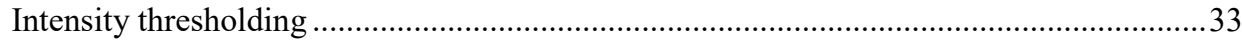

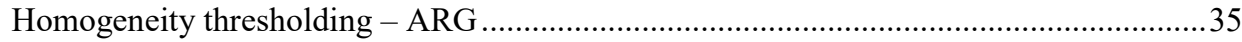

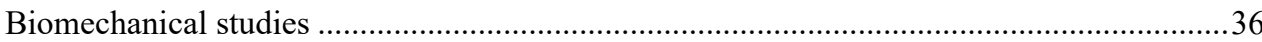

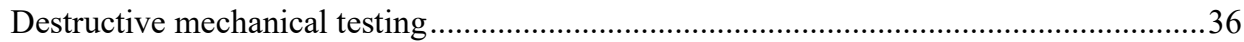

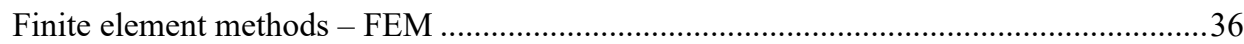

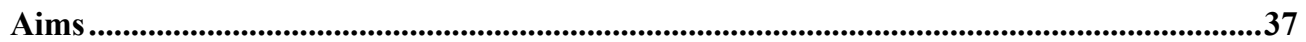


Material and methods ..............................................................................................................................39

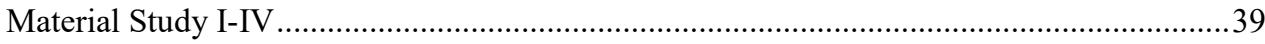

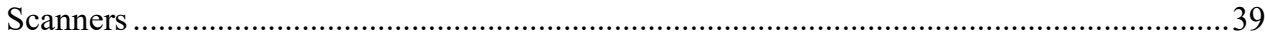

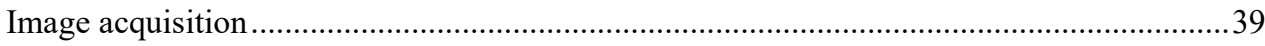

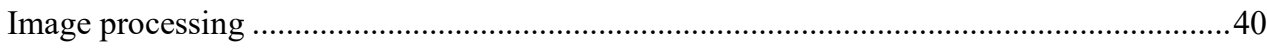

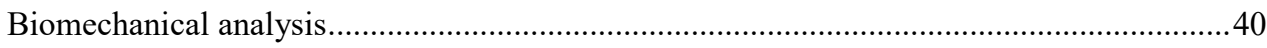

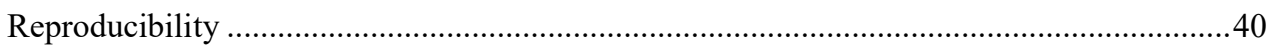

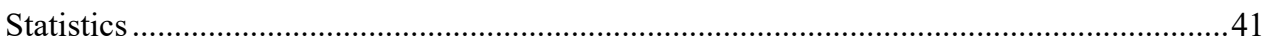

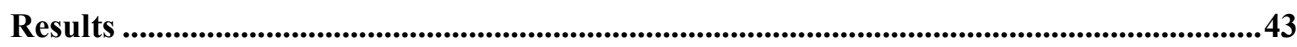

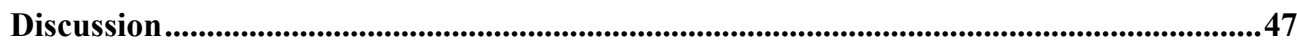

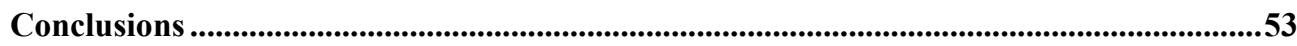

Future perspectives .................................................................................................................................55

References

Appendix (Paper I - IV) 


\begin{abstract}
Trabecular bone structure as well as bone mineral density (BMD) have impact on the biomechanical competence of bone. In osteoporosis-related fractures, there have been shown to exist disconnections in the trabecular network as well as low bone mineral density. Imaging of bone parameters is therefore of importance in detecting osteoporosis. One available imaging device is cone-beam computed tomography (CBCT). This device is often used in pre-operative imaging of dental implants, for which the trabecular network also has great importance.
\end{abstract}

Fourteen or 15 trabecular bone specimens from the radius were imaged for conducting this in vitro project.

The imaging data from one dual-energy X-ray absorptiometry (DXA), two multi-slice computed tomography (MSCT), one high-resolution peripheral quantitative computed tomography (HR-pQCT) and four CBCT devices were segmented using an in-house developed code based on homogeneity thresholding. Seven trabecular microarchitecture parameters, as well as two trabecular bone stiffness parameters, were computed from the segmented data. Measurements from micro-computed tomography (micro-CT) data of the same bone specimens were regarded as gold standard.

Correlations between MSCT and micro-CT data showed great variations, depending on device, imaging parameters and between the bone parameters. Only the bone-volume fraction (BV/TV) parameter was stable with strong correlations. Regarding both HR-pQCT and CBCT, the correlations to micro-CT were strong for bone structure parameters as well as bone stiffness parameters. The CBCT device 3D Accuitomo showed the strongest correlations, but overestimated BV/TV more than three times compared to micro-CT. The imaging protocol most often used in clinical imaging practice at our clinic demonstrated strong correlations as well as low radiation dose.

CBCT data of trabecular bone can be used for analysing trabecular bone properties, like bone microstructure and bone biomechanics, showing strong correlations to the reference method of micro-CT. The results depend on choice of CBCT device as well as segmentation method used. The in-house developed code based on homogeneity thresholding is appropriate for CBCT data. The overestimations of BV/TV must be considered when estimating bone properties in future clinical dental implant and osteoporosis research. 


\section{Populärvetenskaplig sammanfattning}

Skelettet har stor betydelse för vårt dagliga liv. Frånsett tandemalj så är ben den hårdaste vävnaden i vår kropp. Två av skelettets huvudsakliga funktioner är att vara stöd för våra mjukvävnader och skydda våra inre organ från skada. Benvävnad består förutom av mineral, som kalcium och fosfat, också av benmärg och kollagena fibrer. Kalciumfosfat gör benvävnaden hård för att klara belastning. I skelettet sker ombyggnad under hela vår livslängd. Makroskopiskt ses två olika sorters ben: kortikalt (kompakt) respektive trabekulärt (spongiöst) ben. Det kortikala benet, som utgör cirka $80 \%$ av skelettets kalkmängd, är det hårda yttre skalet. Det trabekulära benet består av bentrabekler (tunna benbalkar) av olika tjocklek och form vilka löper kors och tvärs i olika riktningar. Detta bennätverk ökar skelettets styrka mot olika sorters belastningar. Det kortikala benet innehåller inte så många benceller och bara cirka $4 \%$ av kortikalt ben byggs om årligen. Det trabekulära benet innehåller många benceller och har en ombyggnadstakt på cirka $28 \%$ per år. Olika delar av vårt skelett består av olika mycket kortikalt och trabekulärt ben. Exempelvis består kotkropparna i våra ryggkotor av $25 \%$ kortikalt och $75 \%$ trabekulärt ben, medan underarmens yttersta del till $95 \%$ består av kortikalt och till bara $5 \%$ av trabekulärt ben.

Människans skelett får sin maximala benmassa ungefär vid 25 års ålder och kvarstår relativt oförändrad till i 40-årsåldern. Senare i livet minskar benmassan och för kvinnor sker en tydlig minskning kring övergångsåldern, mycket på grund av de minskade östrogennivåerna. När benmassan minskar blir skelettet svagare och det kan uppstå brott redan efter mindre trauman, s.k. lågkraftsfrakturer. Det uppstår skelettsvikt, som kan jämföras med hjärtsvikt, njursvikt m.fl., och också kallas benskörhet eller osteoporos. Vanligaste metoden att mäta benmassan i skelettet är DXA (dual energy x-ray absorptiometry). Med denna metod får mängden kortikalt ben stor betydelse, medan de tunna benbalkarnas utseende inuti benet inte kan bedömas. Vid osteoporos är påverkan på det trabekulära bennätverket stor eftersom där sker snabbast benombyggnad. Benbalkarna blir färre, tunnare och det uppstår brott i förbindelserna mellan de olika benbalkarna. Benets motståndskraft mot våld minskar. Det påverkar framför allt ryggkotorna som huvudsakligen består av trabekulärt ben. Förändringarna i benbalkarna kan dock också ses i ben i andra delar av kroppen såsom underben och underarm. Dessa delar av skelettet kallas det perifera skelettet.

Trabekulär benstruktur kan undersökas med mikroskopi på benbitar som plockats ut ur kroppen. Med mikro-datortomografi (mikro-DT), som är en form av skiktröntgen, kan man tredimensionellt (3D) avbilda trabekulärt ben. Undersökning med mikro-DT tar upp till några timmar, och kan endast göras på benbitar eller sövda försöksdjur av storlek liten råtta. En annan metod där perifera skelett kan undersökas i 3D är högupplösande perifer kvantitativ datortomografi (HR-pQCT). En sådan undersökning av underarm eller underben tar cirka 3 minuter och avbildar benbalkar som är $0,08 \mathrm{~mm}$ eller större. HR-pQCT finns endast på speciella kliniker och finns t.ex. bara på ett sjukhus i Sverige. Ytterligare en metod där man kan avbilda benbalkar i 3D, med en tjocklek på cirka $0,08 \mathrm{~mm}$, är högupplösande dental volymtomografi eller cone-beam computed tomography (CBCT). Tekniken introducerades i slutet av 1990-talet, men har utvecklats snabbt och maskiner finns nu på såväl röntgenkliniker som på tandläkarhögskolor och hos specialistutbildade och privatpraktiserande tandläkare. Det finns många olika fabrikat och deras förmåga att avbilda tunna benbalkar med hög kvalitet varierar. 
Tanken med vårt projekt var att undersöka hur väl man kan bedöma benbalkarnas utseende med hjälp av olika tekniker av datortomografi. För att kunna göra dessa bedömningar utan att utsätta personer för röntgenstrålning har vi haft tillgång till 15 benbitar från underarm, vilka donerats för forskningsändamål. Dessa benbitar har undersökts med mikro-DT med en upplösning på $0,02 \mathrm{~mm}$, som får gälla som sanningen om hur benbalkarna ser ut. Därefter har de undersökts med fyra olika modeller av CBCT. Med den CBCT som finns på röntgenkliniken i Linköping har de undersökts med ett tiotal olika inställningar för att få fram bästa möjliga bildkvalitet till så låg röntgenstråldos som möjligt. Dessutom har benbitarna undersökts med DXA och med HR-pQCT. De har även undersökts med multi-snittdatortomografi (MSCT), som är den vanligaste formen av skiktröntgen.

Analyserna av benbalkarna har gjorts med ett bildbehandlingsprogram utvecklat i Linköping och görs oberoende av personliga, subjektiva bedömningar. Mjukvaran levererar ett antal siffermått på benbalkarnas egenskaper, såsom tjocklek, antal, täthet samt antalet förbindelser och s.k. lösa ändar.

Då en annan tanke med studien var att studera benets hållfasthet och styrka har benbalkarnas tjocklek, antal och hur de är orienterade studerats med en matematisk metod som kallas finita elementmetoden (FEM), vilken med hjälp av datorsimulering kan beräkna ett materials mekaniska egenskaper. På så sätt har benbitarnas styvhet och motstånd mot skjuvkrafter kunnat bedömas utan att benbitarna har behövt förstöras.

Kliniska studier, utförda vid andra forskningscentra, har visat att benstruktur och benhållfasthet kan bedömas med hjälp av HR-pQCT. Vårt projekt visar att det är möjligt att bedöma det trabekulära benet även med dental CBCT och att korrelationen mellan CBCT och mikro-DT då är stark. Bedömningen är därför att man med denna undersökningsmetod borde kunna göra tillförlitliga beräkningar också av benets struktur och hållfasthet i framtida kliniska studier. 


\section{List of publications}

\section{Papers included in the thesis}

Referred to as their Roman numerals.

I. Trabecular bone structure parameters from 3D image processing of clinical multislice and cone-beam computed tomography data: Klintström, E., Smedby, Ö., Moreno, R., Brismar, T.B. (2014). Skeletal radiology, 43 (2), 197-204. doi: 10.1007/s00256-013-1766-5

II. Trabecular bone histomorphometric measurements and contrast-to-noise ratio in CBCT: Klintström, E., Smedby, Ö., Klintström, B., Brismar, T.B., Moreno, R. (2014). Dentomaxillofacial Radiology, 43(8), 20140196. doi:10.1259/dmfr.20140196

III. Predicting trabecular bone stiffness from clinical cone-beam CT and HR-pQCT data; an in vitro study using finite element analysis: Klintström, E., Klintström, B., Moreno, R., Brismar, T.B., Pahr, D.H., Smedby, Ö. (2016). PloS one, 11(8), e 0161101. doi:10.1371/journal.pone 0161101

IV. Direct Estimation of Trabecular Bone Strength Using Cone-Beam Computed Tomography: Klintström, E., Klintström, B., Moreno, R., Pahr, D.H., Smedby, Ö. (2017). Submitted

Papers published as part of the project, not included in the thesis

- Anisotropy estimation of trabecular bone in gray-scale: Comparison between conebeam and micro-computed tomography data: Moreno, R., Borga M., Klintström, E., Brismar, T.B., Smedby, Ö. (2015). In Developments in Medical Image Processing and Computational Vision (pp. 207-220). Springer International Publishing. doi:10.1007/9783-319-13407-9_13

- Correlations between fabric tensors computed on cone-beam and micro-computed tomography images: Moreno, R., Borga M., Klintström, E., Brismar, T.B., Smedby, Ö. (2013). Computational Vision and Medical image Processing (VIPIMAGE) 393-398

- Feature space Clustering for Trabecular Bone Segmentation: Klintström, B., Klintström, E., Moreno, R., Smedby, Ö. (2017). In Scandinavium conference of Image Analysis (pp 65-75). Springer Cham. doi:10.1007/978-3-319-59129-2_6

- Granulometry-Based Trabecular Bone Segmentation: Chowdhury, M.; Klintström, B., Klintström, E., Smedby, Ö., Moreno, R. (2017). In Scandinavium conference of Image Analysis (pp 65-75). Springer Cham. doi:10.1007/978-3-319-59129-2_9

Scientific paper related to, but not part of, the project

- Bone Density at Implant Sites and Its Relationship to Assessment of Bone Quality and Treatment Outcome: Bergkvist, G., Sahlholm, S., Klintström, E., Lindh, C. INTERNATIONAL JOURNAL OF ORAL and MAXILLOFACIAL IMPLANTS, 2010, 25(2), 321-328. 
Conference papers published as part of the project

- Three-dimensional image processing for measuring trabecular bone structure parameters: Klintström, E., Moreno, R., Brismar, T.B., Smedby, Ö. (2012). European Association of Dentomaxillofacial Radiology (EADMFR), Leipzig, Germany, June 13-16, 2012.

- Trabecular bone structure parameters from cone beam computed tomography data: Klintström, E., Moreno, R., Brismar, T.B., Smedby, Ö. 27th Congress of the European Society of Head and Neck Radiology (ESHNR 2014), September 25-27, 2014, Marseille, France, 2014.

- Clinical dental cone beam computed tomography - a tool for monitoring trabecular bone structure? Klintström, E., Klintström, B., Brismar, T.B., Smedby, Ö., Moreno, R. European Congress of Radiology (ECR), Vienna, Austria, March 4-8 2015, 2015. doi:10.1594/ecr2015/C-1213 


\section{Author contributions}

\section{Paper I}

Trabecular bone structure parameters from 3D image processing of clinical multi-slice and cone-beam computed tomography data; E. Klintström, Ö. Smedby, R. Moreno, T. Brismar, Skeletal Radiology February 2014

\begin{tabular}{|l|c|c|c|c|}
\hline Contribution\Author & EK & ÖS & RM & TB \\
\hline Idea/hypothesis/design & $\mathrm{x}$ & $\mathrm{x}$ & & $\mathrm{x}$ \\
\hline Project planning & $\mathrm{x}$ & $\mathrm{x}$ & - & - \\
\hline Project implementation & $\mathrm{x}$ & $\mathrm{x}$ & $\mathrm{x}$ & - \\
\hline Analysis/summary & $\mathrm{x}$ & $\mathrm{x}$ & $\mathrm{x}$ & - \\
\hline Manuscript writing: & $\mathrm{x}$ & - & - & - \\
\hline First draft & $\mathrm{x}$ & $\mathrm{x}$ & - & - \\
\hline Main contributor & $\mathrm{x}$ & $\mathrm{x}$ & $\mathrm{x}$ & $\mathrm{x}$ \\
\hline Suggestions/improvements & $\mathrm{x}$ & - & - & - \\
\hline Wrote final version & $\mathrm{x}$ & - & - & - \\
\hline Correspondence with journal &
\end{tabular}

\section{Paper II}

Trabecular bone histomorphometric measurements and contrast-to-noise ratio in CBCT; E. Klintström, Ö. Smedby, B. Klintström, T. Brismar, R. Moreno, Dentomaxillofacial Radiology, 2014

\begin{tabular}{|l|c|c|c|c|c|}
\hline Contribution\Author & EK & ÖS & BK & TB & RM \\
\hline Idea/hypothesis/design & $\mathrm{x}$ & - & - & - & - \\
\hline Project planning & $\mathrm{x}$ & $\mathrm{x}$ & - & - & - \\
\hline Project implementation & $\mathrm{x}$ & $\mathrm{x}$ & $\mathrm{x}$ & - & $\mathrm{x}$ \\
\hline Analysis/summary & $\mathrm{x}$ & $\mathrm{x}$ & $\mathrm{x}$ & - & $\mathrm{x}$ \\
\hline Manuscript writing: & $\mathrm{x}$ & - & - & - & - \\
\hline First draft & $\mathrm{x}$ & - & - & - & - \\
\hline Main contributor & $\mathrm{x}$ & $\mathrm{x}$ & $\mathrm{x}$ & $\mathrm{x}$ & $\mathrm{x}$ \\
\hline Suggestions/improvements & $\mathrm{x}$ & - & - & - & - \\
\hline Wrote final version & $\mathrm{x}$ & - & - & - & - \\
\hline Correspondence with journal &
\end{tabular}




\section{Paper III}

Predicting Trabecular Bone Stiffness from Clinical Cone-Beam and HR-pQCT data; an in Vitro Study using Finite Element Analysis; E. Klintström, B. Klintström, R. Moreno, T. Brismar, D. H. Pahr, Ö. Smedby, PLoS One, 2016

\begin{tabular}{|l|c|c|c|c|c|c|}
\hline \multicolumn{1}{|c|}{ Contribution/Author } & EK & $\mathrm{BK}$ & $\mathrm{RM}$ & $\mathrm{TB}$ & $\mathrm{DPH}$ & $\mathrm{O} S$ \\
\hline Idea/hypothesis/design & $\mathrm{x}$ & $\mathrm{x}$ & $\mathrm{x}$ & $\mathrm{x}$ & - & $\mathrm{x}$ \\
\hline Project planning & $\mathrm{x}$ & - & - & - & - & $\mathrm{x}$ \\
\hline Project implementation & $\mathrm{x}$ & $\mathrm{x}$ & $\mathrm{x}$ & - & - & $\mathrm{x}$ \\
\hline Analysis/summary & $\mathrm{x}$ & $\mathrm{x}$ & $\mathrm{x}$ & - & - & $\mathrm{x}$ \\
\hline Development of software for bone segmentation & - & $\mathrm{x}$ & $\mathrm{x}$ & - & - & - \\
\hline FEM-analysis & - & - & - & - & $\mathrm{x}$ & - \\
\hline Manuscript writing: & $\mathrm{x}$ & - & - & - & - & - \\
\hline First draft & $\mathrm{x}$ & - & - & - & - & - \\
\hline Main contributor & $\mathrm{x}$ & $\mathrm{x}$ & $\mathrm{x}$ & $\mathrm{x}$ & $\mathrm{x}$ & $\mathrm{x}$ \\
\hline Suggestions/improvements & $\mathrm{x}$ & - & - & - & - & - \\
\hline Wrote final version & $\mathrm{x}$ & $\mathrm{x})$ & - & - & - & - \\
\hline Correspondence with journal & \multicolumn{1}{|l}{}
\end{tabular}

\section{Paper IV}

Direct Estimation of Trabecular Bone Strength Using Cone-Beam Computed Tomography, E. Klintström, B. Klintström, D. H. Pahr, Ö. Smedby, R. Moreno, Submitted

\begin{tabular}{|l|c|c|c|c|c|}
\hline Contribution/Author & EK & BK & DPH & ÖS & RM \\
\hline Idea/hypothesis/design & $\mathrm{x}$ & $\mathrm{x}$ & - & $\mathrm{x}$ & $\mathrm{x}$ \\
\hline Project planning & $\mathrm{x}$ & - & - & $\mathrm{x}$ & $\mathrm{x}$ \\
\hline Project implementation & $\mathrm{x}$ & $\mathrm{x}$ & - & $\mathrm{x}$ & $\mathrm{x}$ \\
\hline Analysis/summary & $\mathrm{x}$ & $\mathrm{x}$ & $\mathrm{x}$ & $\mathrm{x}$ & $\mathrm{x}$ \\
\hline Development of software for bone segmentation & - & $\mathrm{x}$ & - & - & $\mathrm{x}$ \\
\hline FEM-analysis & - & - & $\mathrm{x}$ & - & - \\
\hline Manuscript writing: & $\mathrm{x}$ & - & - & - & $(\mathrm{x})$ \\
\hline First draft & $\mathrm{x}$ & - & - & - & - \\
\hline Main contributor & $\mathrm{x}$ & $\mathrm{x}$ & $\mathrm{x}$ & $\mathrm{x}$ & $\mathrm{x}$ \\
\hline Suggestions/improvements & $\mathrm{x}$ & - & - & - & - \\
\hline Wrote final version & $\mathrm{x}$ & - & - & - & - \\
\hline Correspondence with journal & \multicolumn{1}{|l}{}
\end{tabular}




\section{Abbreviations}

ARG automated region growing

BMC bone mineral content

BMD bone mineral density

$\mathrm{BV} / \mathrm{TV}$ bone volume over total volume

CBCT cone-beam computed tomography

CKD chronic kidney disease

CNR contrast-to-noise ratio

CT computed tomography

CTDI computed tomography dose index

DXA dual-energy X-ray absorptiometry

DLP dose length product

DMT destructive mechanical testing

FE finite element

FEM finite element methods

FOV field of view

FRAX tool for clinically predicting future fracture risk

HR-pQCT high resolution peripheral quantitative computed tomography

HU Hounsfield unit

KAP kerma area product

$\mathrm{mA}$ milliampere

mAs milliampere $\mathrm{x}$ seconds

micro-CT micro-computed tomography

MRI magnetic resonance imaging
MSCT multi-slice computed tomography

$\mathrm{MPa}$ megapascal

$\mathrm{mSv} \quad$ millisievert

NIH National Institute of Health

Otsu a binary segmentation method

pQCT peripheral quantitative computed tomography

Pixel picture element

RAM random access memory

ROI region of interest

SD standard deviation

SSM Statens

strålsäkerhetsmyndighet

T-score reference for bone quality

TMJ temporo-mandibular joints

Tb.N trabecular number

Tb.Nd trabecular nodes

TBS trabecular bone score

Tb.Sc trabecular spacing

Tb.Sp trabecular separation

Tb.Th trabecular thickness

Tb.Tm trabecular termini

VOI volume of interest

Voxel volume element

2D two-dimensional

3D three-dimensional

$\mu$-CT micro-computed tomography 


\section{Acknowledgements}

Örjan Smedby, my main supervisor. Thank you for all your support during the years and thank you for encouraging me to continue believing that my dissertation day finally would come. It was easier when you were in Linköping, but you have made it work well also from KTH in Stockholm.

Rodrigo Moreno, my supervisor. Thanks for answering all my questions and e-mails very quickly and for enlighten me about image processing: always in a friendly way, despite me asking the same questions over again. I miss the time when I could so easily step into your office in Linköping. Good luck at KTH.

Torkel Brismar, my supervisor. Your ideas, your input on my research and your comments to all manuscripts have been very important, useful and "right on target".

Dieter Pahr, my co-author. Thanks for sharing your knowledge in finite element methods with me, a subject not included in my daily work basis.

To IMH, and especially to Maria Engström. You have given me friendly and valuable support in my struggle on the way.

Anna Spångéus and Mischa Woisetschläger for reading my thesis and providing me important input. Sharing interest in bone research with you, is for me a nice bonus.

Radiology Department at University hospital Linköping and County Council of Östergötland. I am thankful for be given the opportunity to finalize my dissertation.

Johan, Lilian, Petter, Anders, Maria, Marie and all other people at CMIV. Thank you for all help during the years and for your contribution to make CMIV such a welcoming part of my daily work and for providing such a nice environment for "FIKA".

Birgitta Stenström, my mentor in radiology and my own "guru" in this subject. Thank you for sharing your knowledge. And even more thank you for being such a good friend and for taking you the time to always listen to me and support me. I admire you.

Anette, Anette, Anita, Carina, Catarina, Karin and Mona at "Odont" for always being my supporting friends and for being so qualified at your work thus making my own work so much easier.

Pia Säfström, my former boss and present friend. Thanks for being such a supporting and straightforward leader and a very good and reliable friend.

Bea Kovascovics, my very best friend at work. Thank you for being around to encourage me over and over again. It has been a joy attending so many interesting conferences together, where you have shared your advanced knowledge always as a fun and easy traveller companion. You really are a true friend.

Hannibal Sökjer, I am so grateful to you for teaching me head and neck radiology in your calm and secure way thus making me rely in myself.

Anna Borg, my young colleague. It is so fun to train you in maxillo-facial radiology. Your enthusiasm and curiosity for radiology inspires me every day. I think your personality and intelligence will turn you into "one of the best" in the field.

All my colleagues at the division of Neuro/Odont and all people at the Radiology Department at University hospital in Linköping for the positive attitude you bring to work, making workdays more joyful. 
Annicka Carlsson, my radiology colleague and friend. Thanks for staying in touch despite my, for the moment, short answers to your messages and e-mails. Hopefully there will be time for longer conversations soon.

Ulla Lasson for being my friend from my first day at work at Folktandvården, Linköping, more than 35 years ago, and for all Midsummers and New Year Eves we have spent together with you and Ulf (who I also count as one of my best friends).

All my friends amongst people I meet outside my daily work: relatives, neighbours, Tomaskören, SFOR, "Vingänget", the people at Folktandvården and Käkkliniken, people at the gym and other friendly people. When I think about you, it remembers me that life includes many nice activities besides work.

Magnus $\mathrm{W}$ at Aktiva rehab for helping me getting to know my body and for making me remember that I really like training.

Theodora A at Feelgood for all your friendly guidance the last year and for giving me tools for getting back on track again.

My sister Helena and Peter, Richard and Joakim. I am so glad that we live so close by, making Christmas and Birthday celebrations together easy, relaxing and fun. Drinking champagne together with you on short notice, our friends, is for me always a very positive event.

Kjell, my uncle and extra father "in memorian". My up-bringing at the farm on Gotland, with hard work, together with your friendly attitude towards animals and people has had a great impact on me and who I am. Work hard, be friendly, never say that something is impossible and always try your best. I miss you but can feel your strong support.

Finally, my family, I love you all so much. You are the best in my life.

Rebecka, my daughter. I love you and I have learnt so much from you. The two weeks Stefan and I had together with you and Fredrik with hiking, swimming and watching the sun eclipse was breath-taking and enabled me to relax from work. I know that you enjoy Canada, but I hope you will move closer to us soon, so I can get hugs from you more often.

Helena, my daughter. I love you. It is so relaxing for me to visit you and Sverker and I really like when you show me all nice places and restaurants in Stockholm. Thank you for being you and for giving me new views and perspectives on things which I have got stuck into.

Samuel, my son and our little angel. You are always in our hearts.

Benjamin, my son and my co-author. I love you. Thank you for never (?) getting tired of my questions and for your fantastic enthusiasm regarding our research project despite my despair at times. Thank you for providing me all the nice images in the thesis and for always cheering on me.

Stefan, my wonderful husband, friend, father to our four fantastic children, cycle repairer, upcoming hiking partner and much, much more. Thanks for all loving support through all our years together. Life has not always been easy, but with love and respect for each other, even hard times pass. I know that I can trust and rely in you all times. I love you. 


\section{Preface}

Like most other dentists, I have a focus on sub-mm details that results in everyday questions like:

- Has this caries decay progressed from the enamel into the dentin?

- Is this root-canal filling at the root end?

- Is there some dentin left between the root resorption and the tooth pulp?

- Is this cyst involving one, two or more teeth?

The treatment of each patient depends on the answers to these questions. The decision can in some cases alter the treatment from no treatment at all, to the removal of many teeth.

After working as a general dentist for more than fifteen years, I studied three more years to become a maxillo-facial radiologist. This meant more diagnostics and even tinier details. In 2003, a new device for imaging the jaws, the CBCT, was introduced in Gothenburg that made it possible to image details as small as $0.1 \mathrm{~mm}$. Suddenly I could see details like the "gubernaculum dentis" the connective tissue strand that is supposed to guide the tooth into its position in the jaws. A detail I had heard about throughout my carrier, but never previous seen. This fascinated me. I could also see the tiny bone network in the jaws. I did like to look at all this, but at the same time I wanted to use this new information for something potentially useful for patients. My PhD studies started in collaboration with Gothenburg.

In 2008, a CBCT was installed in Linköping with a resolution of $0.08 \mathrm{~mm}$. This resulted in that I, when imaging wisdom teeth, cystic lesions and/or dental implants, could see the trabecular bone network as part of the examinations. Many years later, and in collaboration with people in Linköping, Växjö, Stockholm, Göteborg, Jönköping, and Wien specialized in osteoporosis, radiology, biomechanical analysis, statistics and image analysis, I think we have a result. Now, after all hours of research, our method is going to be validated in research in vivo. 


\section{Introduction}

\section{Skeleton}

The skeleton is an important structure in the human body, not only providing protection for the vital inner organs, permitting movement of the body but also as a reservoir for minerals and being an environment for the blood-producing cells in the marrow of the bones.

The skeleton consists of 213 bones divided in four different types: long bones, short bones, flat bones and irregular bones [1]. There are mainly two types of bone tissue: cortical and trabecular. The cortical bone is the outer, hard shell and the trabecular or cancellous bone is the inner part, consisting of a network of bone trabeculae with different shapes and thicknesses. Of the total bone mass in the skeleton, there is $80 \%$ cortical and $20 \%$ trabecular bone. Different skeleton parts contain different amounts of cortical and trabecular bone. For comparison the vertebrae are $75 \%$ trabecular and $25 \%$ cortical while the most distal part of the radius is $95 \%$ cortical and only $5 \%$ trabecular [2].

The strength of the skeleton depends on both the bone mineral content and the internal structure of the different bones [3, 4]. It is therefore of importance to study both the total bone mass and the trabecular bone structure. In cortical bone, the bone mass is high, $80-90 \%$ is mineral, while only $15-20 \%$ is mineral in the trabecular part of the bones. The major part of the physiological loading in limbs depends on the cortical bone mass while the network in the trabecular part plays a more important role for forces like when stumbling without falling [5]. Both the cortical and the trabecular part play an important role in bone strength and there is not one single bone architecture type optimal for the strength [6]. Instead there are different architectural solutions, optimized for the mechanical requirements in different parts of the body.

\section{Bone}

\section{Bone tissue}

Bone tissue is an active, metabolic organ where remodelling takes place throughout the whole life span [7]. Trabecular bone has a higher turnover rate than the cortical bone and therefore plays a more important role in the metabolic function. In adults, the annual turnover rate is about $4 \%$ for cortical bone while about $28 \%$ of the trabecular bone is remodelled every year [8].

In the remodelling phases of bone there are mainly three types of bone cells involved [9]. The osteoclasts (the bone eating cells) are large cells, that are responsible for resorption of old bone and of bone that is exposed to biomechanical forces. Only about $1-2 \%$ of the bone cells in the adult skeleton are osteoclasts [10]. The resorption phase takes about 4 weeks which is the approximate lifespan for an osteoclast. The osteoblasts are the cells that replaces the resorbed bone with new bone matrix. This matrix is at first a collagenous tissue that gradually gets more and more mineralised. This bone formation phase, in an healthy adult, takes about 4-6 months [2]. As the bone formation progresses, the osteoblasts become embedded in the bone matrix they have synthesised and become osteocytes [11], buried alive [12]. Already in 1960 Frost stated that these bone cells make up $90-95 \%$ of the total amount of cells in the adult skeleton and that there are about 20,000 to 80,000 cells per $\mathrm{mm}^{3}$ bone [13]. These osteocytes are connected to each other through tiny canals that function as a network 
sensitive for mechanical loading [10]. Earlier knowledge proclaimed that when the osteoblasts became embedded most of them underwent programmed cell death; apoptosis $[12,14]$ More resent research shows that the embedded osteocytes take an active role in bone remodelling $[10,15]$. They are multifunctional cells that control the bone remodelling process by regulations of osteoblasts as well as osteoclasts. The osteocytes are connected to each other through tiny canaliculi through which their dendritic processes can communicate.

\section{Cortical bone}

The cortical bone is dense, solid and contains high amounts of mineral. Cortical bone is synonymous to compact bone, which can be a misleading term, because the cortical bone is penetrated by both Haversian and Volkmanns canals through which the bone gets its blood supply. In lacunes in the cortical bone there are lots of osteocytes. Previously, when those osteocytes were thought to be inactive cells, only the periosteal (outside of the cortical bone) and the endosteal (inside of the cortical bone) were considered to be of interest for bone remodelling. More recent research shows that the active osteocytes play an important role in the remodelling process and the interest for cortical bone has increased. When apoptotic osteocytes accumulate in the cortical bone, it may lead to osteonecrosis and forming of intracortical porosity lacunes [16]. Also on the inside of the canals bone resorption takes place, resulting in strip-shaped porosities. In the femur (thigh-bone) the porosities have diameters between $60-400 \mu \mathrm{m}$ and in the radius diameters of about $200 \mu \mathrm{m}$ [17]. Over $60 \%$ of the porosities have diameters less than $100 \mu \mathrm{m}$ [11]. The cortical porosity has been reliably imaged in vitro and measured by microscopy and micro-computed tomography (micro-CT) [18]. In vivo imaging and research of porosities is dependent on high-resolution techniques and currently the technique most often used is high-resolution peripheral computed tomography (HR-pQCT). Recent in vivo studies show that such porosities impact the mechanical properties of bone and are related to fractures [19].

\section{Trabecular bone}

The inner, trabecular part is, according to Nazarin et al "Light as a Feather, Stiff as a Board" [20]. Trabecular bone can rapidly adapt to mechanical loading and optimize its structure in order to be able to bear high loads with as little tissue as possible. Many fractures occur at skeletal parts mainly consisting of trabecular bone, like the vertebrae. It is therefore of high importance to ascertain how to image and measure the structure of the trabecular bone. In specimens, this can be done by microscopy and by micro-CT and there is good agreement between those two methods [21]. To describe the structure and enable comparison between studies it is important to use the same nomenclature $[22,23]$. Important structure parameters to measure are the following that can be seen in Fig 1.

- Trabecular nodes (Tb.Nd); are the number of trabecular intersections per $\mathrm{mm}^{3}$

- Trabecular termini (Tb.Tm); are the number of free ends of trabeculae per $\mathrm{mm}^{3}$

- Trabecular separation (Tb.Sp); is the thickness of the spaces between the trabeculae in $\mathrm{mm}$

- Trabecular spacing (Tb.Sc); is the distance between the midlines of the trabeculae in $\mathrm{mm}$ 
- Trabecular number (Tb.N); are the number of trabeculae in $1 / \mathrm{mm}$ (not illustrated in Fig. 1)

- Trabecular thickness (Tb.Th); is the thickness of the trabecular structures in mm

- Bone volume over total volume (BV/TV); is measured by dividing the number of voxels classified as bone by the total number of voxels in the volume (not illustrated in Fig. 1)

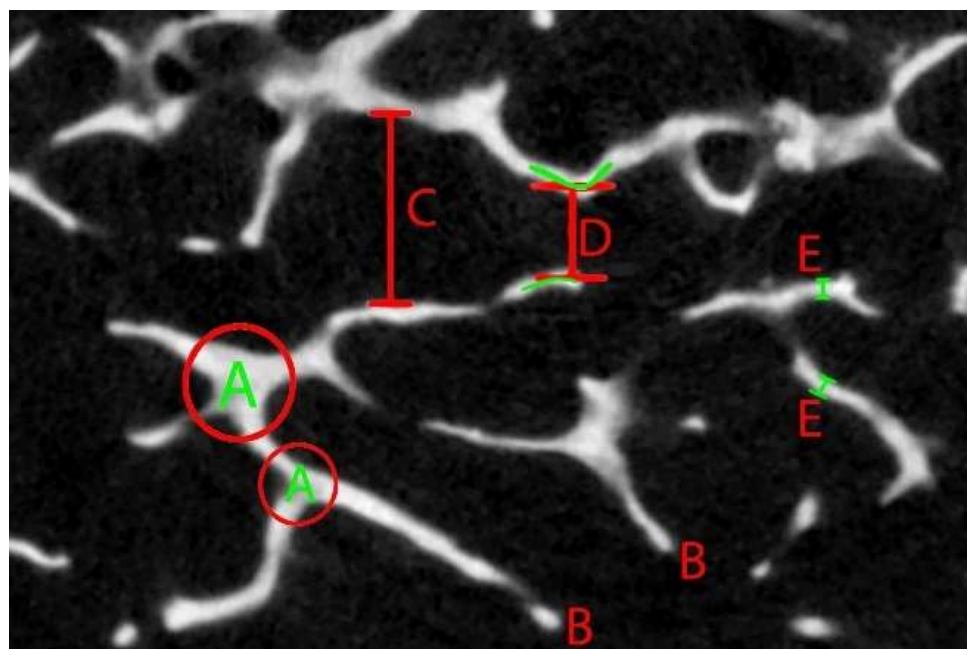

Figure 1. Definition of bone structure parameters. Trabecular nodes (A). Trabecular termini (B). Trabecular separation (C). Trabecular spacing (D). Trabecular thickness (E).

The thickness of a bone trabeculae, in the radius, as measured by micro-CT is about $0.1 \mathrm{~mm}$ $(100 \mu \mathrm{m})[24,25]$. To be able to image and measure the trabecular network, the technique used has to work in $3 \mathrm{D}$ and have resolutions that can image the thickness of a trabecula or even thinner structures.

\section{Bone structure and dental implants}

The stability of implants in the jaws is related to the bone health and quality [26, 27].

Traditionally cortical bone is preferred as an implant site, however trabecular bone sites show tendency to, in time become more cortical around the metal implants, hence having a primary cortical implant bed is not crucial for implant survival. In the upper jaw, the alveolar bone (the part that contains the teeth) is mostly trabecular with only a thin cortical rim at the top of the alveolar crest. The quality and health of the trabecular bone is therefore of high importance. There is a strong correlation between the grey values (density) of the bone and the primary stability of the implants [28-30] which is known to predict the implant survival rate [31-33]. Cone beam computed tomography (CBCT) is often the imaging method of choice before implant installation and the method has a high accuracy for linear measurements [34-36] but lower for grey value measurements [37-39]. Individuals with osteoporosis have lower primary implant stability compared to non-osteoporotic individuals $[30]$. 


\section{Osteoporosis - Skeletal failure}

According to the National Institutes of Health (NIH) Osteoporosis and Related Bone Diseases National Resource Centre,

(https://www.niams.nih.gov/Health_Info/Bone/Osteoporosis/bone mass.pdf) one can look at human bone tissue as a bank account, where it is possible to make deposits and withdrawals throughout life. By the age of about 18 for girls and 20 for boys, approximately $90 \%$ of the bone tissue has been acquired. $26 \%$ of the calcium amount in the adult skeleton is acquired during two years around the peak skeletal growth in adolescence [40]. Therefore, the years of childhood and adolescence are of great importance for making the skeleton strong. Up to the age of about 25 , there is continuing growth of the skeleton and the maximum amount of bone is reached, which is often mentioned as "peak bone mass". For healthy women, the bone mass remains almost unchanged between this age and the years just before the menopause. Rather rapid loss of bone mass occurs during the first few years after menopause [41, 42], which continues but with a slower rate, throughout life. This often leads to a more fragile skeleton with risk for skeletal failures and fractures. Factors having great impact on the bone mass include gender, ethnic group, hormone levels, nutrition, physical activity and smoking [43-45]. The three latter can be influenced by the individuals and their way of living/daily habits. Smoking is highly associated with bone loss. Physical activity has a positive effect on bone mass. In older women (75-85 years of age) with low bone mineral density (BMD) resistance training for six months resulted in a significant increase in cortical bone density at the radial shaft [46]. Physical activity also decreases the risk for falls in elderly people, which reduces fracture risk $[47,48]$.

$\mathrm{NIH}$ has introduced an operational definition of osteoporosis based on the BMD, which can be measured by dual energy x-ray absorptiometry (DXA) [49-51]. BMD reflects the total bone amount and rather reflects more the cortical bone, than the trabecular bone amount. The peak BMD of a healthy 30-year-old adult, serves as the reference for bone quality, defined as T-score 0 .

(https://www.niams.nih.gov/Health_Info/Bone/Bone_Health/bone mass measure.pdf). The T-score for an individual is calculated as the difference between the measured BMD of the actual individual and the mean BMD in healthy young adults of the same gender, divided by the standard deviation (SD) for the healthy young adult population. If the T-score is rated as 0 , the BMD is equal to the norm of a healthy young adult. A T-score above -1 is considered normal or healthy. If the T-score is between -1 and -2.5 , it indicates osteopenia, and a $\mathrm{T}$ score of -2.5 or lower is considered as osteoporosis $[52,53]$. Examples of DXA images can be seen in Fig. 2.

In summary, the lower the T-score, the lower is the bone mass, the more severe is the osteoporosis and thus the risk for skeletal failure. 


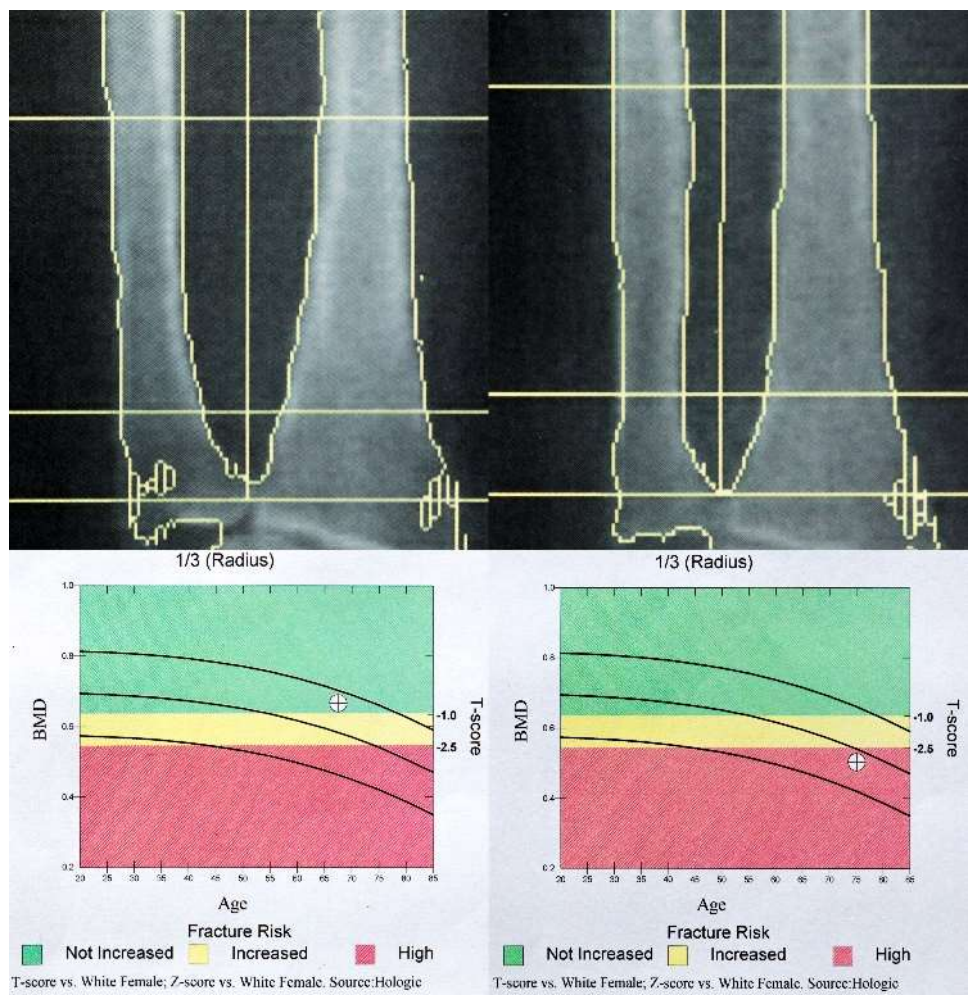

Figure 2. DXA imaging and measurements of the radius. Skeletal healthy 67 -year old woman with a Tscore over -1 to the left. Osteoporotic 76-year old woman to the right with a T-score below -2.5.

Courtesy of Anna Spångéus at Linköping University, Linköping Sweden.

Osteoporosis is an ongoing process, throughout life, where multiple pathogenic processes may cause an increased loss of bone mass and changes in the microarchitecture of the skeletal structure [54]. When the bone mass decreases, the skeleton becomes more fragile, osteoporotic, which increases the risk for fractures. Hip fractures are common in osteoporotic skeleton and result in major health costs and great suffering for the affected individuals [55]. Sweden, Denmark, Norway and Austria are among countries having the highest incidence of hip fractures in women in the world [56]. Fractures are not only caused by fragile skeleton, but is also influenced by the patient's risk to fall. This could be due to impaired balance which is often seen in the elderly [57]. Therefore older persons with a T-score, in the osteopenic range (between -1 and -2,5), may experience more fractures due to their higher tendencies of falling [58]. Another tool for clinically predicting future fracture risk is FRAX ${ }^{\circledR}[59]$. This is a web-based tool that combines several known strong risk factors for osteoporotic fractures to calculate patients risk of major osteoporotic fracture as well as for hip fracture. The risk factors in FRAX includes for example previous low energy fracture, parental history of hip fracture, gender, glucocorticoid medication, rheumatoid arthritis and smoking. Risk score could be calculated either with or without known BMD, however including BMD in the calculations will make them more adequate.

Osteoporosis associated with the normal aging process is called primary osteoporosis. In addition to primary osteoporosis, there are also secondary forms of osteoporosis caused by 
diseases or medications with a negative effect on bone. One example is in the case of chronic kidney diseases (CKD), that affect about $10 \%$ in a general population, and often lead to severe secondary osteoporosis. CKD patients seem predisposed for fractures that are linked to much higher morbidity and mortality rates than fractures observed in the normal population $[60,61]$.

In conclusion there are many factors that may impact the risk for fractures [49, 62-67] and regardless of whether osteoporosis is to be counted as a disease or not, it is one risk factor among many others [68]. One may therefore discuss whether a name-shift from osteoporosis to skeletal failure, could be motivated.

\section{Imaging techniques}

\section{Dual-energy $x$-ray absorptiometry - DXA}

The most common imaging technique for measuring and diagnosing fragile skeleton and assess the future fracture risk for an individual, is DXA $[49,69,70]$. This method gives the bone mineral density (BMD) in the specific bone area, measured in $\mathrm{g} / \mathrm{cm}^{2}$. BMD is a major determinant of bone strength but many low violence fractures occur in individuals with the osteopenic or normal BMD [51]. An examination with DXA can also give information about the bone mineral content (BMC) in $\mathrm{g}$ in the measured area. This is a non-invasive, twodimensional (2D) technique that uses ionizing radiation for measuring the bone mineral in the skeleton.

The name, dual-energy, refers to the fact that the X-ray tube supplies photons of two energy levels, e.g. of $70 \mathrm{kV}$ and $140 \mathrm{kV}$. The ratio of attenuation of these high respective low-energy beams allows the identification and separation of bone from soft tissue, based on the density of each pixel. From the areas that consist of bone, in selected regions of interest (ROIs), calculations of both BMD and BMC can be made. Due to the limited spatial resolution and the $2 \mathrm{D}$ technique it is not possible to distinguish between cortical and trabecular bone or assess trabecular bone micro-structure. Another limitation is that the mathematical algorithm used for the measurement of BMD assume homogeneity of the soft tissue. But as the soft tissue is heterogeneous this assumption is a source of error [71]. More recently, trabecular bone score (TBS) computed from the grey-level matrix of DXA devices has been proposed. However, the impact of TBS is still controversial [72-74].

The body parts that are most often scanned by DXA are the hip and the lumbar spine (vertebrae L1-L4), as demonstrated in Fig. 3. 


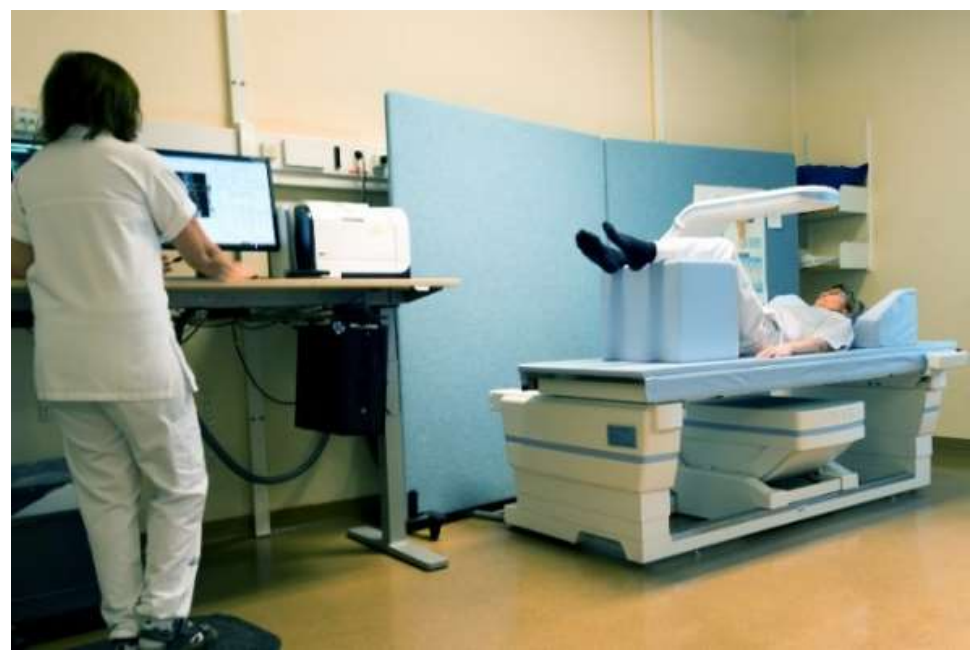

Figure 3. DXA-examination of the lumbar spine. Courtesy of Marit Svensson at the Osteoporosis unit, Linköping University hospital, Linköping, Sweden.

Other parts scanned may be the forearm (Fig 2) and in certain cases the whole body is scanned. Measurements of BMD is currently the most accepted standard for clinical assessment of the risk for bone fractures, often in conjunction with the FRAX score, and increased risk for fractures is clearly related to decreased BMD [75].

DXA-imaging is considered to be a low-dose radiation technique, with an effective dose from a hip and spine examination varying between 1 and $20 \mu \mathrm{Sv}$ [76], and at a low economical cost [77]. For comparison the dose from a dental x-ray examination, consisting of two intraoral images, is $5 \mu \mathrm{Sv}$, the annual background radiation in Sweden is 1-2 mSv (i.e 1000-2000 $\mu \mathrm{Sv})$ and a Western Europe-New York round trip entails a dose of about $100 \mu \mathrm{Sv}$ (http://www.stralsakerhetsmyndigheten.se/Om-myndigheten/Aktuellt---Bilagor/Resultat-franmatningarna-i-Sverige).

\section{Computed tomography - CT}

Computed tomography is a diagnostic imaging technique where fan beam shaped X-rays passing through an object provides you cross-sectional grey-scale images of the object (Fig. 4 and 5). The x-ray source rotates around the object and the x-rays generated from the source pass through the object, e.g. the human body. The x-rays passing the object will be measured by a detector. There are multiple projections for each rotation. The digital values sent from the detector, describing the amount of radiation passing through the tissue and reaching the detector, will be analysed by complex reconstruction algorithms demanding advanced computer systems. Due to differences in attenuation in tissues, these complex mathematical computations, enable the possibility to differ tissues from each other and to assign them different CT- or Hounsfield Unit (HU)-values [78]. The HU-values are obtained from a linear transformation of the measured attenuation coefficients. The radio-density of distilled water at standard temperature and pressure (STP) is defined as $0 \mathrm{HU}$ and air has a HU-value of -1000 . 
A Multi-Slice CT (MSCT) (Fig. 4), is a device where the patient passes through the CT scanner while the circular opening (gantry) rotates and takes a volume of images of the body part inside the gantry. This makes it possible to image objects in 3D. Reconstruction of images with different thickness and different in-plane resolution is possible by MSCT, which makes the technique useful for diagnostic medical imaging.

The advantages of MSCT in diagnostics for identifying persons at risk for having future osteoporotic fractures, are the higher resolution and the 3D technique, making it easier to identify earlier suffered fractures. This is important, because prior experience of fractures is one risk factor among others being at risk for future fractures. Although the resolution is high, with voxels having sides of about $0,2 \mathrm{~mm}$, imaging the trabecular and cortical bone structure needs resolutions of $0.1 \mathrm{~mm}$ or less [79], making MSCT for the moment promising, but not ideal for such imaging [80, 81].

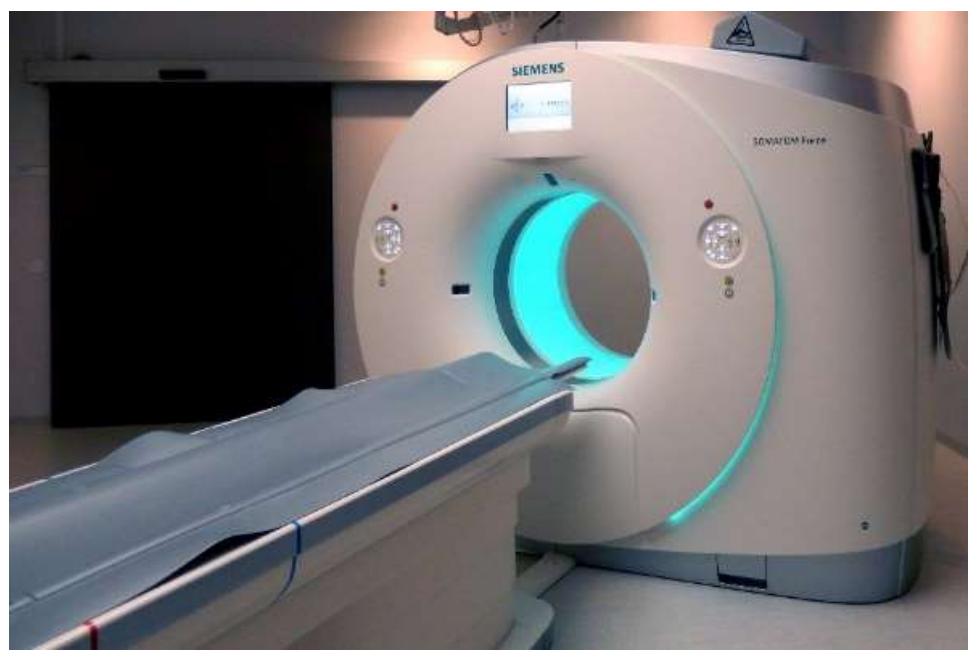

Figure 4. MSCT device at Center of Medical Image Science and Visualization (CMIV), Linköping. Courtesy of Petter Quick at CMIV, Linköping, Sweden.

A disadvantage of MSCT is the much higher radiation dose compared to DXA. According to the report from European Commission of Radiation Protection in 2015 including 36

European countries, (https://ec.europa.eu/energy/sites/ener/files/documents/RP180web.pdf), the annual frequency of x-ray procedures (including dental) were about 660 millions. CT examinations were responsible for about $10 \%$ of the total number of the radiology examinations, but contributed to almost $60 \%$ of the total radiation dose. For comparison, the radiation dose of a DXA of the lower spine is between 1 and $20 \mu \mathrm{Sv}$ [76] and the dose for a $\mathrm{CT}$ of the spine is, according to the same report from the European Commission, about 10 $\mathrm{mSv}$. For comparison the dose for a CT of the abdomen, where the lower part of the spine is in the FOV, is about $8 \mathrm{mSv}$ [82]. Low dose imaging MSCT of e.g. the chest and lumbar spine is, however, a field of current research where studies have found that radiation doses can be decreased while remaining a high image quality $[83,84]$. For a visual demonstration of differences in noise and the visualisation of trabecular bone structure between conventional dose and low dose protocol in the lumbar spine, see Fig. 5. 


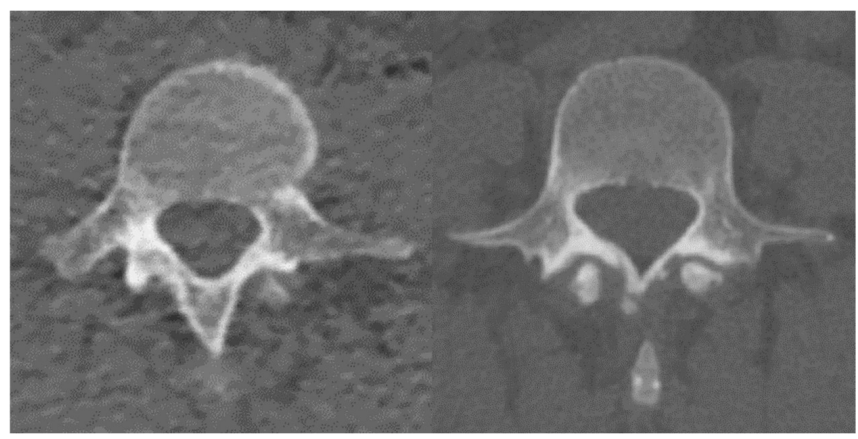

Figure 5. Lumbar spine imaged with a low dose protocol at a tube current of $20 \mathrm{~mA}$ and a tube voltage of $120 \mathrm{kV}$ to the left. Radiation dose in DLP (dose length product) is $42.90 \mathrm{mGycm}$. Lumbar spine. of a person at the same age, imaged with a conventional CT-protocol at a tube current of $180 \mathrm{~mA}$ and a tube voltage of $120 \mathrm{kV}$ to the right. DLP for the examination is $361.50 \mathrm{mGycm}$. Images from CMIV, Linköping, Sweden.

High-resolution peripheral quantitative computed tomography - HR-pQCT
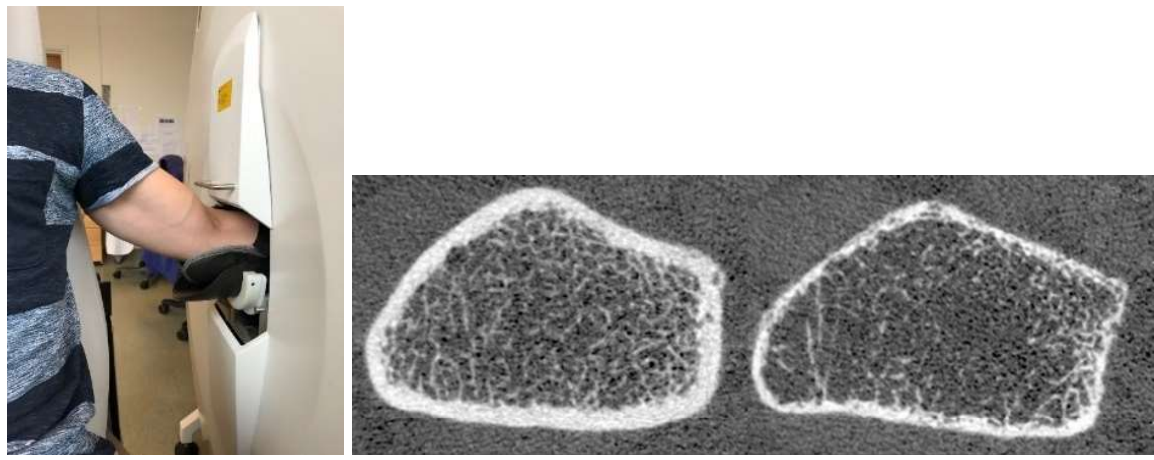

Figure 6 . Wrist imaged by HR-pQCT. To the left, demonstrating the examination. In the middle, an image slice of a healthy individual and to the right an image slice of an osteoporotic individual. Courtesy of Daniel Sundh at University of Gothenburg, Sweden.

Imaging bone micro-structure in vivo is possible by HR-pQCT of the peripheral skeleton, such as the wrist (Fig. 6) and heel. A precursor to HR-pQCT was pQCT, introduced in the 1990's [85, 86]. HR-pQCT was introduced in the beginning of this century [87]. By this technique, it is possible to measure volume BMD and micro-architectural morphology as well as some mechanical properties of the imaged bone [88-92]. The isotropic voxel resolution for most HR-pQCT devices is down to $82 \mu \mathrm{m}$, allowing the bone trabeculae to be visualised properly. There is good agreement between HR-pQCT and the gold standard micro-CT regarding trabecular bone parameters like Tb.N, Tb.Th and Tb.Sp [24, 87]. In vivo studies have shown that trabecular bone volume fraction derived by HR-pQCT data is independently associated with prevalent fractures [66]. Other bone quality factors, like cortical porosity, have been imaged and measured by HR-pQCT, but as $60 \%$ of the pores have diameters of less than $100 \mu \mathrm{m}$ this may lead to an underestimation of the porosities [17,93]. Research is ongoing with a recently introduced device working with isotropic voxels of $61 \mu \mathrm{m}$ [94]. This 
is promising for future in vivo studies for estimations of cortical porosities and trabecular bone microarchitecture.

\section{Micro-computed tomography - micro-CT or $\mu C T$}

Micro-CT, like other CT-techniques, uses X-rays for producing images of an object. The first device was introduced in the 1980's [95]. The voxels from these devices are isotropic and it is possible to create $3 \mathrm{D}$ volumes from the data. Imaged voxel sizes in modern devices can be below $10 \mu \mathrm{m}$ and the method is used both in medical imaging and for industrial purposes. The round opening, gantry, between the x-ray source and the detector is small, approximately $50-80 \mathrm{~mm}$ in diameter, allowing only small animals to be imaged in vivo (Fig. 7).

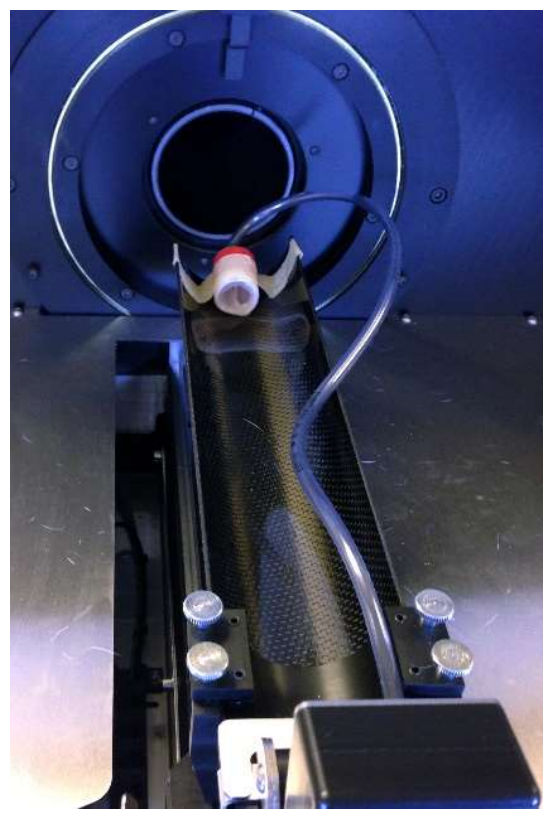

Figure 7. Image demonstrating the small gantry opening of a micro-CT machine. For comparison, the device close to the gantry is a mask for anaesthesia of small research animals. (Private image).

The imaging time is considerably long, often hours, and the radiation dose high [96]. These factors make micro-CT unsuitable for medical imaging of patients or study persons. Micro$\mathrm{CT}$ is of high importance for imaging of tissue samples in research projects where it is regarded as gold standard for imaging of bone microarchitecture [21, 23]. 
Dental CBCT is an image technique that uses a cone-beam shaped x-ray beam instead of the fan-beam shaped beam, used in conventional MSCT modalities (Fig. 8,9).

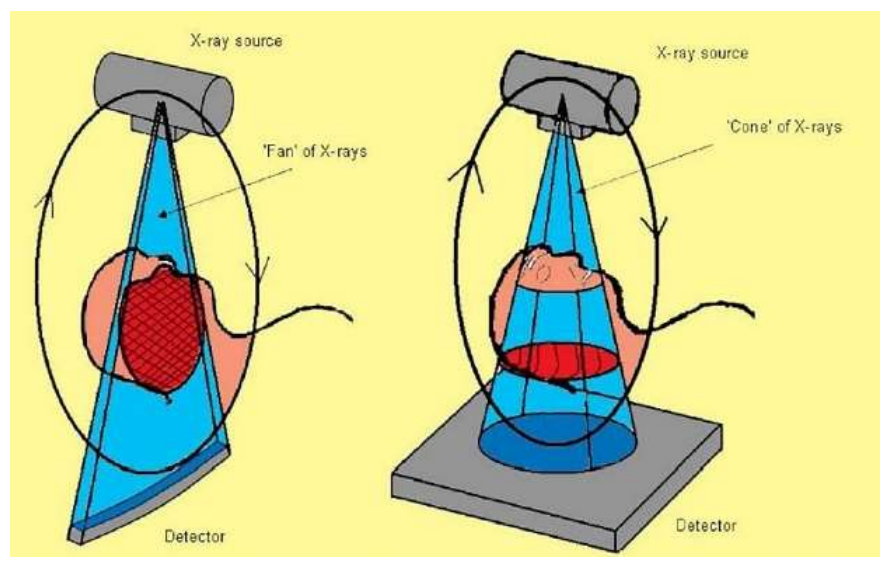

Figure 8. Image demonstrating the difference between fan beam CT used in conventional CT (left) and cone beam CT (right) in the supine (lying down on the back) position. Courtesy of Scarfe WC, Farman AG, Sukovic P. Clinical Applications of Cone-Beam Computed Tomography in Dental Practice. J Can Dent Assoc. 2006;72(1):75-80. Reprinted with permission of the Canadian Dental Association.

The technique was first introduced in the end of the last century [97] and is today widely used for imaging of the teeth, jaws, sinuses, middle ear and temporo-mandibular joints (TMJ:s) [98-103]. The mandibular bone has like the radius and other long bones an outer, cortical part that surrounds an inner trabecular part. That makes the mandibular bone an interesting body part for studies in bone structure and strength research.
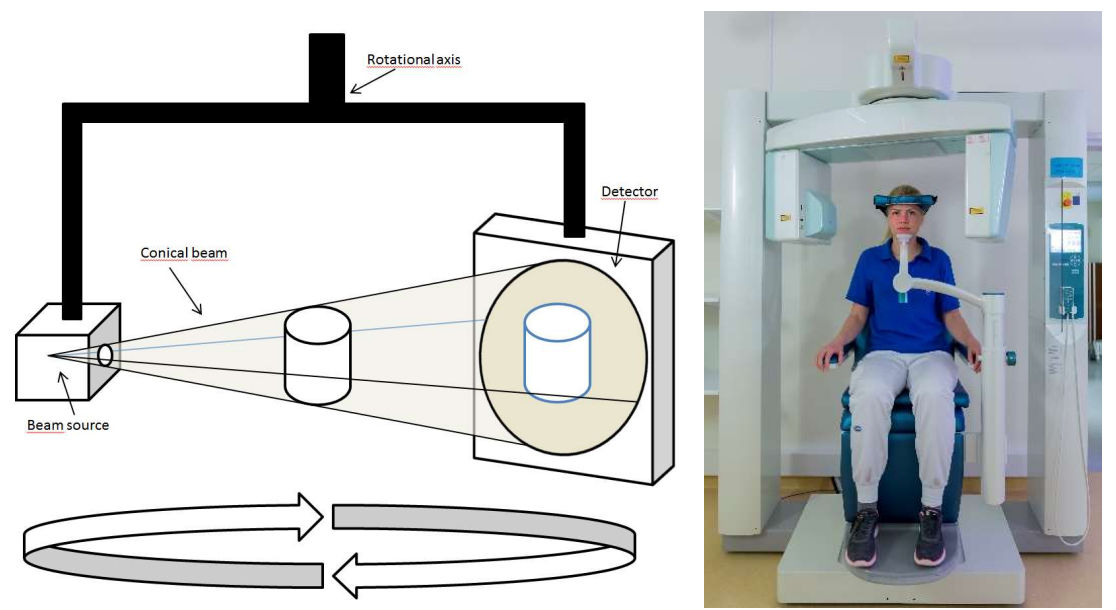

Figure 9. Demonstration of CBCT technique in the sitting position, to the left. Acknowledge to Aron Saar - Own work, CC BY-SA 3.0. To the right demonstration of clinical imaging in the Accuitomo 80. Image, courtesy of Benjamin Klintström. 
There are many brands and manufacturers of CBCT devices [104]. All of them have the cone-beam shaped x-ray beam and isotropic voxels, but they differ in many other ways [105]. There are devices for imaging in the standing and sitting position as well as the supine (lying down on the back) position. There are devices possible for extremity imaging where the person can be either sitting or standing [106-108]. CBCT devices differ e.g. in imaged FOV sizes, rotation degree, tube current settings, tube voltage settings and in resolution (voxel size) (http://www.sedentexct.eu/content/comparison-cbct-machines). The resolution expressed as the sides of the voxels varies between about 75 and $400 \mu \mathrm{m}$. Fig. 10 demonstrates CBCT images with voxel sizes of $80 \mu \mathrm{m}$ and a FOV of $60 \mathrm{~mm}$. Because, as earlier mentioned, the mean thickness of bone trabeculae is approximately $100 \mu \mathrm{m}$, the possibility for imaging those structures strongly varies between the devices. The possibility of imaging bone microstructure with CBCT are highly dependent on the imaging parameters and image resolution and studies show diverse results [109-118].

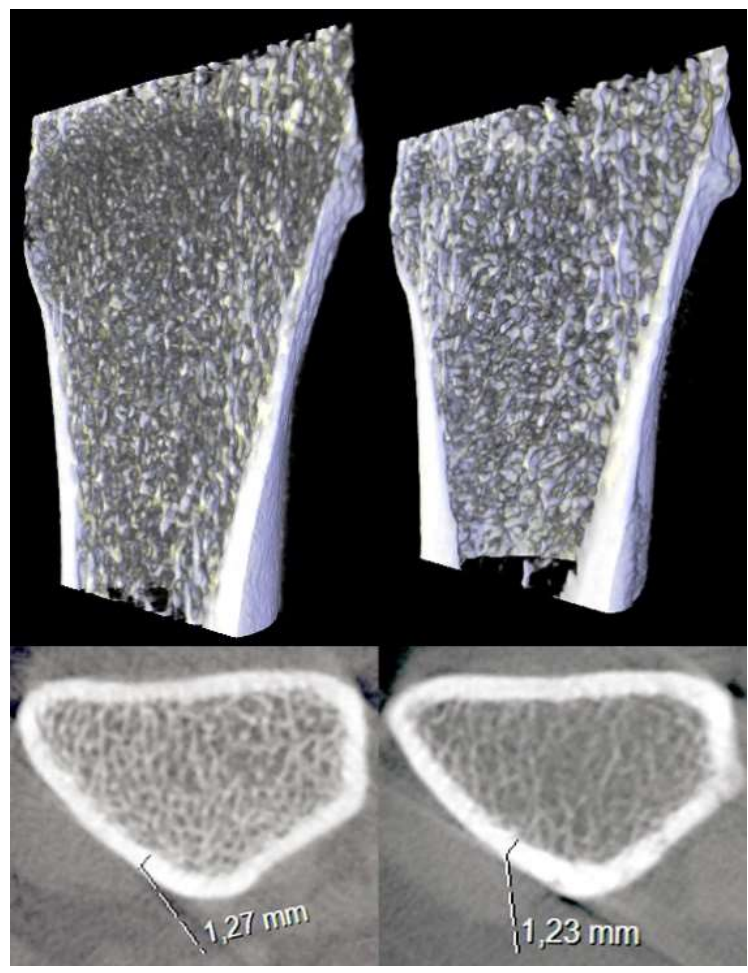

Figure 10. Upper left a 3D rendering of a CBCT (3D Accuitomo 80) examination of the left radius of a 22 -year old healthy male. Upper right of a 57 -year old healthy woman. In the lower row, there are image slices of the same examinations. (Imaging parameters: $85 \mathrm{kV}, 5 \mathrm{~mA}, 80 \mu \mathrm{m}$ voxels, $60 \mathrm{~mm}$ FOV and a 360 degree rotation). Note the sparser trabecular pattern for the older woman. Images from Linköping University Hospital, Sweden.

CBCT is often referred to as a low-dose technique compared to MSCT. For example, a study comparing radiation doses from $\mathrm{CBCT}$ and MSCT demonstrates that the effective radiation dose when imaging a wisdom tooth in the lower jaw by CBCT is $29 \mu \mathrm{Sv}$. When imaging the same region by MSCT, the dose is $474 \mu \mathrm{Sv}$ [119]. However, due to the many changes in imaging parameters possible both for MSCT and for $\mathrm{CBCT}$, the radiation doses show great 
differences. One undisputable fact is that CBCT allows imaging of small cone-shaped FOVs', e.g. $4 \times 4 \mathrm{~cm}$, which reduces the effective dose compared to MSCT [120-122].

A major drawback of CBCT compared to MSCT is that current CBCT devices do not produce calibrated grey-scale values. It is therefore not possible to get HU-values for correctly differentiating between tissues. The devices produce a kind of grey-scale values and some studies suggest that they may be reliable [123, 124], but the values differ between devices as well as on the placement of the object in the imaged FOV [34, 37-39, 114].

\section{Image processing and analysis}

Image analysis aims to extract information of interest from images. This analysis is mainly used for digital images. To be able to extract different components from an image data set, the data must be processed. This process aims to find different shapes or edges, remove noise and/or measure properties of an object. As example, image enhancement is used to remove noise and image segmentation is used to isolate objects or regions of interest. Image data sets are most often data intensive and the use of computers for the analysis is therefore demanded.

Image processing in skeletal failure quantification

Image analysis of medical images, in purpose of detecting individuals at risk of having skeletal failure, requires image processing in many steps. The primary goal is to delineate the bone tissue from other tissues in the imaged object or volume.

One important step in the image analysis is segmentation where the grey-scale images are converted into binary images. In this step, the image processing aims to find the boundary between bone and other tissues. The voxels that are identified as bone will be assigned the value 'one' and the other voxels are assigned the value 'zero', resulting in black-and-white images. Images obtained by low dose CT imaging protocols (MSCT, CBCT as well as HRpQCT) contain more noise compared to high-dose imaging protocols from the same devices, and the image processing will be more demanding and the noise may reduce the possibility of differentiating tissues from each other. Low resolution images, with voxels larger than the bone trabeculae, result in problems with edge detection. Many of the voxels in the periphery of the bone tissue will consist of both bone and soft tissue and the edge between those tissues will be blurred. Both low-dose (Fig. 5, left image) and low-resolution images may negatively impact the possibility to correctly identify the bone voxels which will impact all future processing and analyses.

\section{Intensity thresholding}

Micro-CT, MSCT and HR-pQCT devices provide image data with intensity values. From these values, tissues in e.g. a bone specimen can be separated from each other. This allows the segmentation of hard tissues as bone from soft tissues like muscles and fat and is very useful in image processing for analysis of bone. When the voxels are small (20 $\mu \mathrm{m}$ or less) as in micro-CT, the voxels most often contain only one kind of tissue. In trabecular bone imaging, the voxels will then contain either bone or background. As can be seen in Fig. 11, micro-CT has two separate peaks in the histogram. Segmentation of bone from background may in this type of datasets be solved by fast segmentation methods like Otsu [125]. This segmentation method is based on intensity thresholding and in data sets like the micro-CT data in Fig. 11, the threshold is automatically placed in the valley between the two peaks in 
the histogram. The high peak to the left in the histogram (around 0 units) represents one type of tissue (water) and the much lower peak to the right (around 4000 units) represents the bone voxels. When the voxels are bigger like in for example MSCT, HR-pQCT and CBCT this results in voxels being a mixture of both bone and background and there will not be a pronounced valley between the peaks. This makes the segmentation of bone from background more challenging.

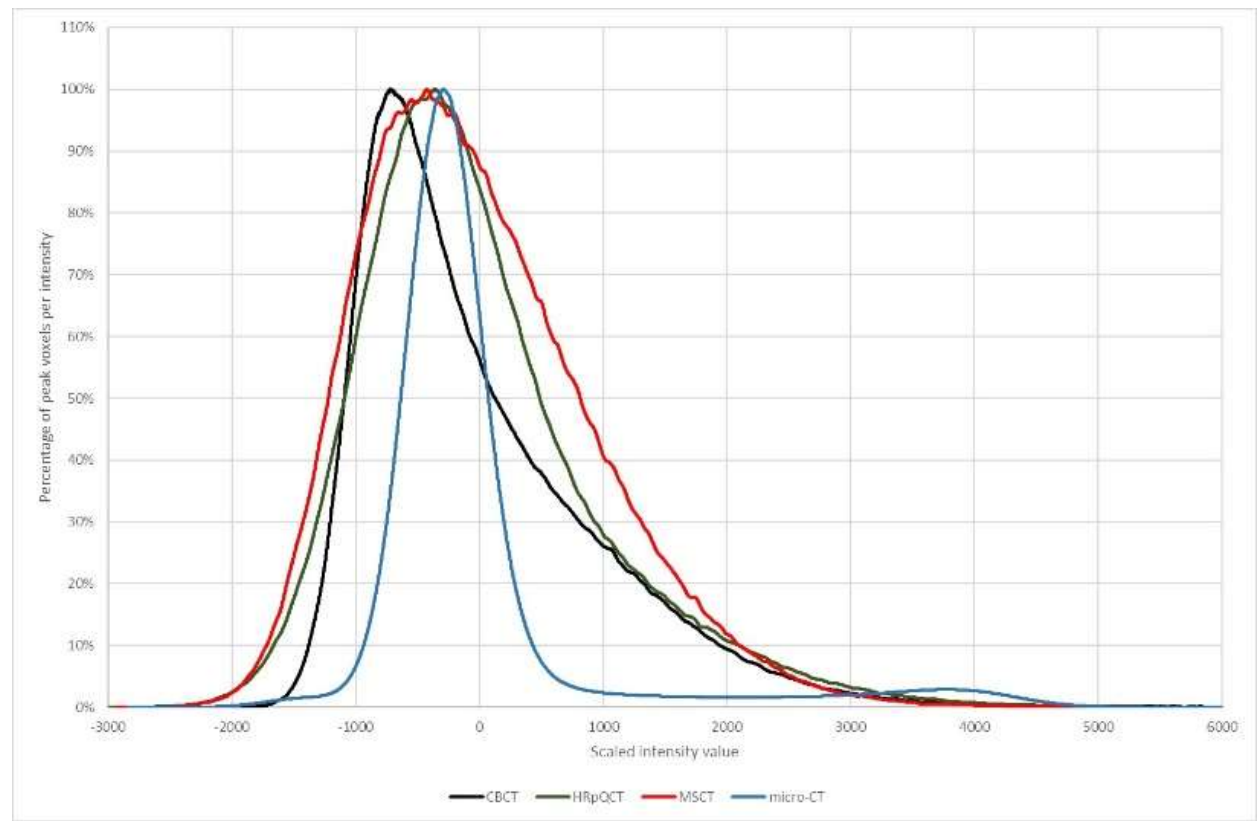

Figure 11. Histograms from four different CT-devices of one of the defatted trabecular radius bone cubes, used in the four studies, consisting of only bone and water.

Image segmentation is a critical step and requires images in $3 \mathrm{D}$ with sufficient quality both regarding resolution and noise as well as a correct chosen threshold. If the threshold is set at a too high level, it will result in an underestimation of the bone amount. A threshold at a too low intensity level will result in an overestimation of the amount of bone (Fig. 12). 


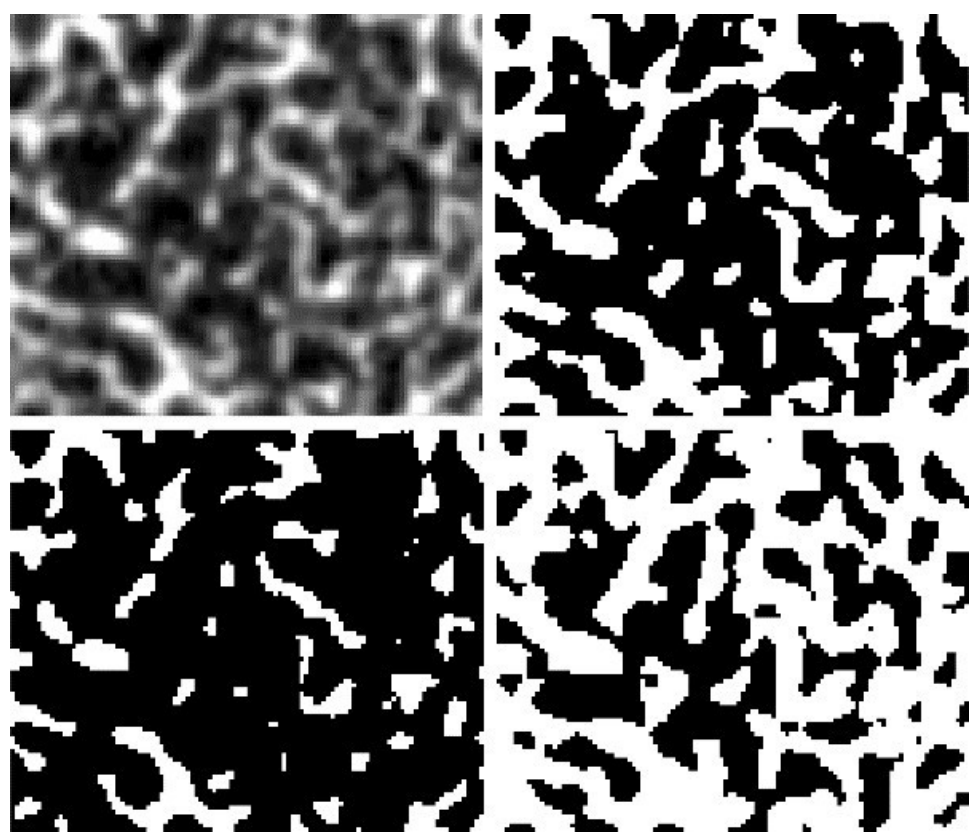

Figure 12. Raw image slice from CBCT (3D Accuitomo 80) of trabecular bone at $80 \mu \mathrm{m}$ resolution (upper left). Binary image of the same slice segmented by correct intensity thresholding (upper right). Binary segmentation of the same slice with a higher threshold, resulting in underestimation of the bone amount (lower left). Binary segmentation of the same slice, with a lower threshold resulting in overestimation of the bone amount (lower right).

\section{Homogeneity thresholding - ARG}

Data from devices that have lower resolution than micro-CT, where there will be many voxels containing both bone and background, intensity thresholding like Otsu [125] may not be ideal for segmenting the data. Other segmentation methods like homogeneity thresholding can be possible solutions. One useful method is the Automated 3D region growing (ARG) algorithm based on an assessment function [126]. With this method, the separation of bone from background starts with a very strict homogeneity threshold to define bone. This results in an underestimation of the bone amount. The process then repeats with more and more permissive thresholds until too many voxels are defined as bone. The strictest homogeneity threshold is defined as the homogeneity of the original bone seeds. Those seeds clearly consist only of bone. The most permissive threshold results in a great over-estimation of the bone amount. Between those thresholds multiple iterations are performed and the iteration where the assessment function $(f($ seg $))$ :

$$
f(\text { seg })=\sqrt[2]{\sum\left(\text { seg }_{\text {bone }}-\mu_{\text {bone }}\right)^{2}+\sum\left(\text { seg } \text { background }-\mu_{\text {background }}\right)^{2}}
$$

reaches its minimum will be used for calculation of the bone structure parameters.

The device, where the separation of bone voxels from the background voxels is most challenging is MSCT [127]. The voxels from this device have sides with a length of about $200 \mu \mathrm{m}$ which will result in many voxels containing partially of bone and partially of background [81]. This will impact both the intensity values and the homogeneity in the voxels. 


\section{Biomechanical studies}

\section{Destructive mechanical testing}

The conceptually simplest method to understand the behaviour of a material under different loadings is destructive mechanical testing (DMT). Such tests are carried out until the material or specimen breaks. By DMT the properties of a material can easily be understood and the process can be filmed by high-speed cameras allowing the process to be carefully studied after the test. The problem is that the method is destructive, resulting in that only one kind of loading can be carried out on each specimen. For materials that can be mass-produced, this is a cost-effective and suitable test. For bone specimens that are unique, destructive testing is not preferable.

\section{Finite element methods - FEM}

Finite element methods (FEM) are mathematical methods making it possible to simulate properties of bone like strength, concentration of mechanical stress (stress) and physical deformation (strain). The methods rely on computers to solve the large sets of equations [128]. Information of bone mineral density (BMD) and bone mineral content (BMC) are important for this mathematical analysis. Information of BMD and BMC can be derived from DXA imaging [129, 130]. To be able to make more correct analyses of the trabecular bone properties, information of the 3D structure is of importance [131]. The availability of CT data increased the usefulness of FEM for the measurements [128]. When predicting bone behaviour, FEM requires that the analysed bone parts are divided into smaller pieces called elements that are equally sized (isotropic) [132]. Finite element analysis (FEA) can be used on these elements to determine stress and strain that occurs in the elements when they are exposed to external forces. FEM methods have been used for in vitro studies since the 1970s and are still evolving [133-136]. In clinical studies, the introduction of pQCT and HR-pQCT for imaging peripheral parts of the body made FEM analyses possible also in vivo [66, 132, 137-140]. 


\section{Aims}

All four studies included in this thesis, are in vitro studies of radius bone specimens.

I. The aim of Study I was to develop a method for quantitative assessment of trabecular bone structure by applying three-dimensional (3D) image processing methods to data acquired with MSCT and CBCT in vitro and to correlate those results to the results from the reference method of $\mu \mathrm{CT}$.

II. The aim of Study II was to evaluate how different CBCT image protocol settings may affect the accuracy in quantifying trabecular bone structure by comparing the results to those of the reference method of $\mu \mathrm{CT}$. The study also aimed to identify differences in CNR between the settings and relate them to the radiation dose.

III. The aim of Study III was to evaluate how closely trabecular bone structure parameters computed on data from CBCT as well as HR-pQCT devices correlated with the reference method of micro-CT. Another aim was to evaluate how well stiffness and shear moduli calculated by finite element analysis from micro-CT data could be predicted from the same data.

IV. The aim of Study IV was to evaluate the ability of three different CBCT machines to assess biomechanical parameters of trabecular bone through FE simulations. Stiffness, including the Young's modulus and shear moduli, was assessed and the measurements and shape of the stiffness tensor were assessed. Corresponding evaluations, using micro-CT were regarded as the reference standard. 


\section{Material and methods}

Material Study I-IV

Radius (human wrist) specimens from human cadavers have been analysed in all four studies. The specimens were donated for medical research at University of California, San Francisco in accordance with the ethical guidelines regulating donations and have been used in previous studies [127, 141, 142]. All the specimens are almost cubic with sides of about 12-15 $\mathrm{mm}$ and they all include slabs of cortical bone, (Fig. 13). The presence of the cortical bone parts makes the orientation of the specimens more correct when performing the different analyses. The radius samples are all stored in separate test tubes filled with water and numbered to differentiate them from each other. Before imaging, each test tube was placed in a glass cylinder with a diameter of $100 \mathrm{~mm}$ filled with paraffin. This was performed to mimic the presence of soft tissue and simulate measurements in vivo. In study I and II, fifteen specimens were analysed. During handling and transportation, one of the specimens was destroyed after study II. Therefore only fourteen specimens were analysed in study III and IV.

\section{Scanners}

The specimens have been imaged by:

- One micro-CT, the $\mu \mathrm{CT} 40$ (SCANCO Medical AG, Bassersdorf, Switzerland) which is a small desktop CT machine for imaging biopsies and other specimens. This data has been regarded as the reference method in all four studies.

- Two different 64-slice MSCT devices: one Siemens Definition (Siemens AG, Erlangen, Germany) and one Light Speed VCT (GE Medical Systems, Milwaukee, WI, USA).

- Four CBCT devices; one 3D Accuitomo 80 and one 3D Accuitomo 170 (J. Morita Mfg. Corp., Kyoto, Japan, one NewTom 5G (QR, Verona, Italy) and one Verity (Planmed, Helsinki, Finland).

- One HR-pQCT XtremeCT, (Scanco Medical AG, Brüttisellen, Switzerland).

- One DXA device using the Discovery A S/N 82934, (Hologic Inc, Bedford, MA).

\section{Image acquisition}

- The images from the micro-CT were acquired using a tube voltage of $70 \mathrm{kVp}$, a tube current of $114 \mu \mathrm{A}$ and an isotropic resolution of $20 \mu \mathrm{m}$.

- The acquisition for the MSCT devices differed in slice thickness and tube current. The images were also reconstructed with two different reconstruction kernels, "bone" and "bone plus" (Table 1 in Study I)

- Regarding CBCT Accuitomo 80 and 170, nine different settings were used with variations in tube voltage, tube current, rotation degree, scanning time, voxel size and FOV (Table 1 in Study II). For the CBCT NewTom 5G, the images were acquired using a peak tube voltage of $110 \mathrm{kV}$, a tube current of 4.2-4.6 mA, a FOV of $60 \mathrm{~mm}$ and an isotropic voxel size of $75 \mu \mathrm{m}$. For the CBCT Verity the images were acquired using a tube voltage of $90 \mathrm{kVp}$, a tube current of $12 \mathrm{~mA}$, a FOV of $160 \mathrm{~mm}$ and the isotropic resolution of $250 \mu \mathrm{m}$ (up sampled to $125 \mu \mathrm{m}$ ).

- The images for HR-pQCT were acquired using a peak tube voltage of $60 \mathrm{kVp}$, a tube current of $0.9 \mu \mathrm{A}, \mathrm{FOV}$ of $126 \mathrm{~mm}$ and an isotropic resolution of $82 \mu \mathrm{m}$. 
- The imaging in the DXA device was performed with a switched pulse dual-energy at $100 \mathrm{kVp}$ and $140 \mathrm{kVp}$

Image processing

After imaging, cubes consisting of only trabecular bone was digitally cut and these cubes were used for the analyses in all four studies. After the digital cutting the remaining trabecular bone cubes had sides of approximately $8 \mathrm{~mm}$, (Fig. 13).

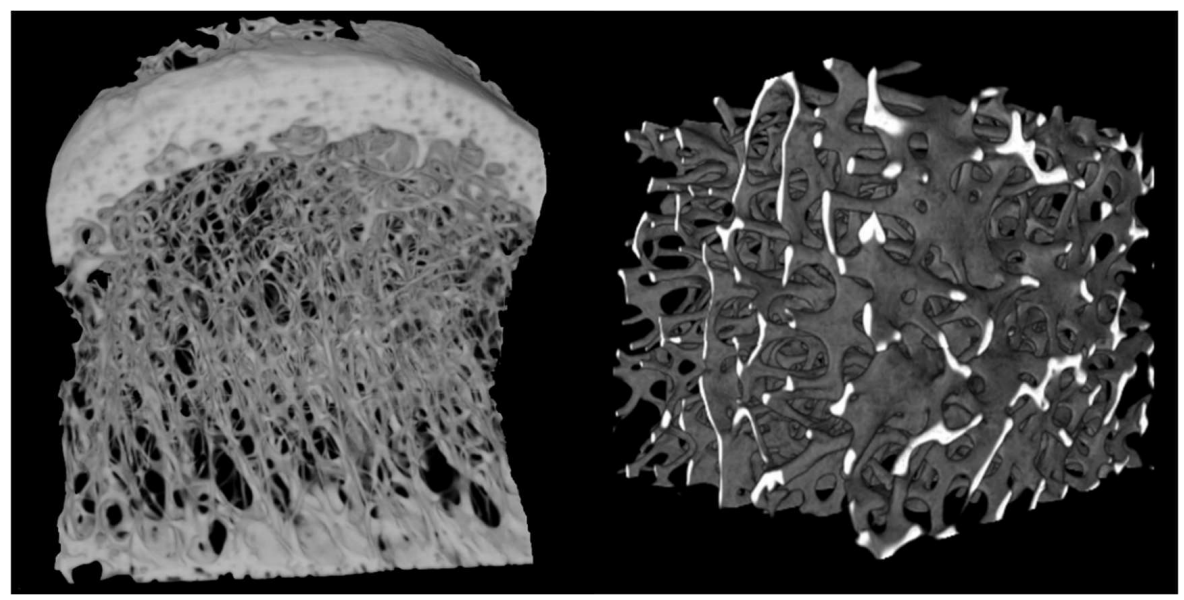

Figure 13. To the left a 3D rendering from micro-CT data of a radius bone specimen with cortical bone included. To the right a $3 \mathrm{D}$ rendering of a bone cube consisting of only trabecular bone (used for the image analyses).

After imaging, we used an automated region growing algorithm (ARG) as well as an intensity thresholding by Otsu for the segmentation of the data (Introduction, Image processing at pages 33-34). The analysis included six to seven bone structure parameters, namely: Bone volume over total volume (BV/TV), Trabecular thickness (Tb.Th), Trabecular separation (Tb.Sp), Trabecular number (Tb.N), Trabecular nodes (Tb.Nd), Trabecular spacing (Tb.Sc), and Trabecular termini (Tb.Tm). Imaged data was segmented and bone structure parameters were calculated using MATLAB ${ }^{\circledR}$ (MathWorks ${ }^{\circledR}$, Natick, MA) with a code developed in house. The computer used was a standard PC with Intel Core i5, CPU at $2.60 \mathrm{GHz}, 4 \mathrm{~GB}$ of RAM and a 64-bit operating system. From the DXA device imaging, the bone mineral density (BMD) in $\mathrm{g} / \mathrm{cm}^{2}$ was derived.

\section{Biomechanical analysis}

Finite element (FE) analysis was performed to measure the biomechanical properties of the trabecular bone cubes. This analysis was based on the segmented micro-CT data, to study if shear and stiffness could be predicted as well as estimated from the HR-pQCT and CBCT data.

\section{Reproducibility}

The reproducibility of the methods was tested by scanning the bone specimens in one of the CBCT devices (3D Accuitomo 80) twice at the same imaging parameters and by performing the analyses of the trabecular bone structure parameters on both image data sets. 


\section{Statistics}

In all four studies, results of the bone structure parameter analyses were presented as mean values with standard deviations. The normal distribution of the dependent variables was tested by Kolmogorov-Smirnov test. Data were compared using Pearson correlation with 95\% confidence intervals. Bland Altman analyses were taken place to test the reproducibility of the methods. For studying the ability to predict biomechanical parameters, linear and stepwise multiple regression analyses of the shear and stiffness predictions as well as tests of the normal distribution of the variables, were performed with the IBM SPSS Statistics program. 


\section{Results}

In the first three studies, trabecular bone structure parameters imaged by CBCT and segmented using the in-house developed code, based on the ARG algorithm, showed strong correlations with the reference data derived by micro-CT. The correlation factors were above 0.90 for Tb.N, Tb.Th and BV/TV when the CBCT device 3D Accuitomo 80 was used. Regarding Tb.Tm, the correlation was below 0.80. All the other bone structure parameters had correlations above 0.80 .

Regarding the mean values, CBCT either overestimated or underestimated some of the parameters compared to the reference method of micro-CT. The parameters BV/TV and $\mathrm{Tb}$.Th were overestimated three to four times while $\mathrm{Tb} . \mathrm{N}$ was underestimated by a factor of three or more (Fig. 14).
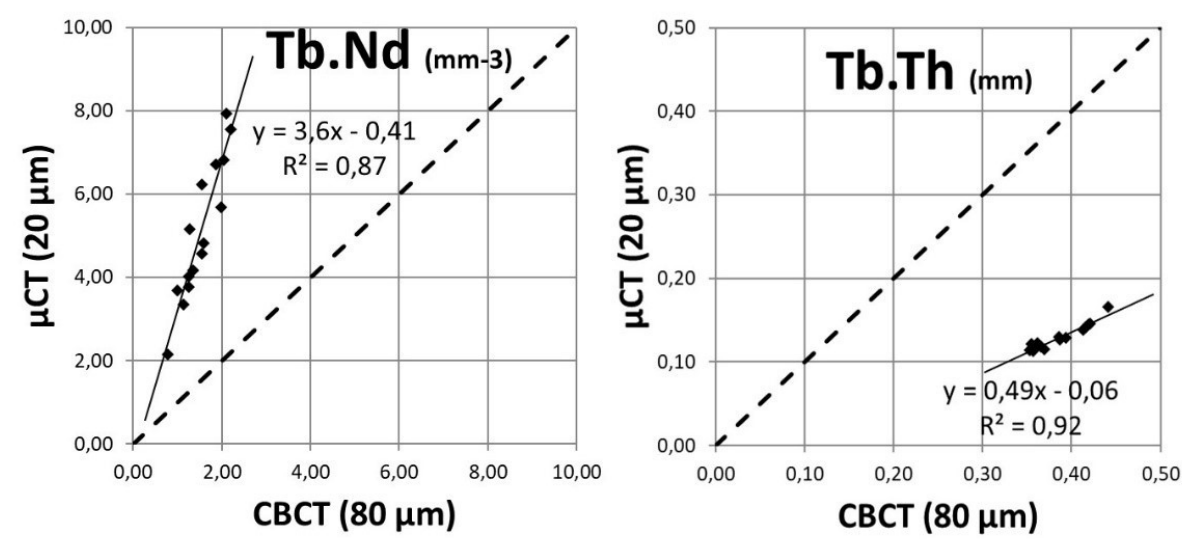

Figure 14. Linear regression analysis of trabecular nodes (mm-3) measured from CBCT and micro-CT (left) and of trabecular thickness (mm) (right). From Klintström E, et al. "Trabecular bone structure parameters from 3D image processing of clinical multi-slice and cone-beam computed tomography data." Skeletal Radiol 2014; 43: 197-204.

Due to the developments of the segmentation algorithm code, when more data were analysed in later studies, there were changes in both correlation factors and mean values between the studies. In the second study when more data from the CBCT device Accuitomo was included, the mean correlation for the six parameters increased. When the code, in Study III, was adjusted to work faster, the correlation mean (for all parameters) became slightly weaker for the Accuitomo.

In the first study, where imaging besides two dental CBCT devices also were performed by two MSCT devices, the results for correlations between micro-CT and MSCT were not encouraging for other parameters than $\mathrm{BV} / \mathrm{TV}$, which showed correlations ranging from 0.87 to 0.94 . Correlations regarding the five other bone parameters showed great variance inbetween the two devices, as well as regarding different imaging settings and between the bone parameters, where correlations varied between 0.06 and 0.91 (Table 1). 
Table 1. Correlations with micro-CT. Pearson correlation coefficient (r) with $95 \%$ confidence limits.

\begin{tabular}{|c|c|c|c|c|}
\hline $\begin{array}{c}\text { MSCT } \\
\text { device }\end{array}$ & $\begin{array}{c}\text { GE Light } \\
\text { speed } \\
\text { Bone }\end{array}$ & $\begin{array}{c}\text { GE Light } \\
\text { speed } \\
\text { Bone plus }\end{array}$ & $\begin{array}{c}\text { Siemens } \\
\text { Definition } \\
600 \mu \mathrm{m}\end{array}$ & $\begin{array}{c}\text { Siemens } \\
\text { Definition } \\
400 \mu \mathrm{m}\end{array}$ \\
\hline Tb.Sp & 0.80 & $\mathbf{0 . 9 1}$ & 0.12 & 0.52 \\
& $(0.49 ; 0.93)$ & $(0.73 ; 0.97)$ & $(-0.42 ; 0.60)$ & $(0.01 ; 0.81)$ \\
\hline Tb.Th & 0.47 & 0.58 & 0.89 & 0.88 \\
& $(-0.06 ; 0.79)$ & $(0.10 ; 0.84)$ & $(0.70 ; 0.96)$ & $(0.66 ; 0.96)$ \\
\hline Tb.N & 0.76 & 0.79 & 0.15 & 0.66 \\
& $(0.41 ; 0.92)$ & $(0.47 ; 0.93)$ & $(-0.39 ; 0.62)$ & $(0.22 ; 0.87)$ \\
\hline BV/TV & 0.89 & $\mathbf{0 . 9 4}$ & $\mathbf{0 . 9 2}$ & 0.87 \\
& $(0.71 ; 0.96)$ & $(0.81 ; 0.98)$ & $(0.76 ; 0.97)$ & $(0.65 ; 0.96)$ \\
\hline Tb.Nd & 0.74 & 0.78 & 0.02 & 0.70 \\
& $(0.36 ; 0.91)$ & $(0.44 ; 0.92)$ & $(-0.53 ; 0.50)$ & $(0.29 ; 0.89)$ \\
\hline Tb.Tm & 0.06 & 0.06 & 0.63 & 0.53 \\
& $(-0.47 ; 0.55)$ & $(-0.46 ; 0.55)$ & $(0.18 ; 0.86)$ & $(0.03 ; 0.82)$ \\
\hline
\end{tabular}

MSCT Multi slice computed tomography; CBCT cone beam computed tomography; $\mathrm{Tb} . \mathrm{Sp}=$ Trabecular separation; Tb.Th = Trabecular thickness; Tb.N = Trabecular number; BV/TV = Bone volume; Tb.Nd = Trabecular number; Tb.Tm = Trabecular termini Bold figures denote correlations above 0.90. Italic figures denote correlations not significantly different from 0 .

The second study focused on the CBCT device 3D Accuitomo, and the influence changes in imaging parameters like tube voltage, tube current, imaging time, imaging voxel size and field of view (FOV) had on the correlations to micro-CT and how those parameters affected the radiation doses and the contrast-to-noise ratios (CNR). The differences in correlations and mean values were only minor in-between most of the nine imaging protocols. Decreasing the imaging time, which also changed the rotation degree from 360 to 180 degrees, had a negative effect on the protocol with the $80 \mu \mathrm{m}$ voxels. The negative effect was clearly visible regarding Tb.Sp, Tb.N and Tb.Tm. Decreasing the imaging time also negatively impacted the CNR, but lowered the radiation dose. The protocol used as clinical standard protocol at our department for implant and dental imaging, showed strong correlations, fair CNR and the second lowest radiation dose.

In the third study, where besides the correlations to micro-CT regarding the trabecular bone structure parameters, also the ability to predict trabecular bone stiffness and shear were studied. Stiffness and shear were predicted using finite element methods (FEM). Two CBCT devices and one HR-pQCT were included using the micro-CT data as the reference. Like in the two previous studies, the data was segmented using the in-house developed code based on the ARG algorithm. The HR-pQCT data was also segmented using the software specially dedicated for this device.

Trabecular bone stiffness and shear could from the CBCT data be predicted with simple linear regression from all trabecular bone structure parameters (except from $\mathrm{Tb}$. Th) having significance levels $<0.05$ (See Tables 3-4 in Study III). The parameter, BV/TV had the highest $\mathrm{R}^{2}$-values varying from 0.70 to 0.93 with a p-value below 0.001 regardless of CTdevice used. In this study, the CBCT device 3D Accuitomo performed better than the NewTom 5G. 
Using stepwise multiple regression, the CBCT device Accuitomo and the HR-pQCT device had $\mathrm{R}^{2}$-values $\geq 0.84$ for predicting both stiffness and shear from the variable Tb.Tm (Table 5 in Study III).

The two CBCT devices overestimated BV/TV and Tb.Th with a factor of close to four (Table 6 in Study III) compared to micro-CT. Tb.Nd was, like in Study II and III, underestimated by CBCT almost four times. HR-pQCT overestimated $\mathrm{Tb}$. Th with a factor of almost three when using the in-house code. HR-pQCT underestimated Tb.Nd more than four times regardless of software used.

There were strong correlations between CBCT Accuitomo and micro-CT regarding the bone structure parameters, with four parameters out of seven having correlations above 0.90 and two above 0.86 (Table 2 in Study III). Only the parameter Tb.Tm had a somewhat lower correlation at 0.79 . The in-house code worked well also regarding HR-pQCT data as well as for CBCT NewTom 5G. Those devices showed slightly weaker correlations to micro-CT than the Accuitomo.

When segmenting HR-pQCT data, using the in-house code, Tb.Tm had a correlation with micro-CT of 0.70 . This parameter had a correlation to micro-CT of -0.27 when using the software dedicated for the HR-pQCT device. Trabecular nodes had almost identical correlations regardless of soft-ware used while the remaining five parameters showed stronger correlations when segmented with dedicated software.

In the fourth study the main interest was to directly estimate biomechanical properties of trabecular bone through CBCT. The data from two dental CBCT devices (3D Accuitomo and NewTom 5G) as well as one CBCT dedicated for extremity imaging (Verity) were segmented using the in-house method based on the ARG algorithm as well as a method based on intensity thresholding (Otsu). The CBCT Accuitomo 80 showed good performance in estimating stiffness (Young's modulus) and shear moduli but was sensitive to the choice of segmentation method. The other two CBCT devices, NewTom 5G and Verity, yielded good but not as strong correlations as the Accuitomo. Both stiffness and shear was overestimated by the CBCT devices compared to the micro-CT estimations. 


\section{Discussion}

Since trabecular bone is of great importance for bone strength, and cone beam computed tomography $(\mathrm{CBCT})$ is a wide-spread technique, the main aim of this thesis was to study the possibilities of CBCT to evaluate trabecular bone properties.

People all over the world suffer from fractures. Often, they are induced by high impact violence, but the cause can also be related to a weak skeleton, a kind of skeletal failure, due to osteoporosis. Denmark, Sweden, Norway and Austria have the highest incidence of hip fractures amongst women in the world (more than 500 per 100,000 annually) [56]. This causes major health costs and great suffering for the affected individuals. The strength of bone, depends on both the mineral content and the bone structure [3, 65, 143-145]. Clinical studies have shown that vertebral fracture risk is correlated to disconnections in the trabecular network [146-148]. Detection of decreased bone strength in an earlier stage, before the first fracture, may lead to correct help for avoiding future fractures. Not only a weak skeleton but also impaired balance increases the risk for fractures [57] and it is shown that physical training to improve balance is of importance amongst the elderly, in fracture prevention [149].

Another aspect on trabecular bone is the impact the bone properties have on dental implants. Primary stability, which measures the mechanical engagement of the implant with the surrounding bone tissue directly after insertion, is an important factor that highly impacts the survival rate of the implants [26, 28, 29, 33].

Considering the above mentioned facts, it seems to be of great importance to find methods that can be used for measurements of both structural and mechanical parameters in the trabecular network, and to do so on individuals in vivo.

Magnetic resonance imaging (MRI) can be used for imaging of the trabecular bone structure in vivo $[92,150-153]$. The method is of high interest since it does not use any radiation. But susceptibility artefacts cause overestimations of the trabeculae [151] and examination time is rather long causing risk for movement artefacts. Besides that, the cost per examination is high compared to many other imaging methods.

CT devices of many different types are used for medical x-ray examinations of living people. According to the report from Swedish Radiation Safety Authority in 2008, the number of xray examinations per year in Sweden was 5.4 million and $30 \%$ of those were CTexaminations [154]. MSCT is the most commonly used CT- device and it would be appealing if the examinations could be used not only in diagnostics of medical diseases but also for structural and biomechanical measurements of the trabecular bone in the imaged FOV. MSCT devices can produce images with voxels having side lengths of about $0.2 \mathrm{~mm}$ which results in difficulties of depicting the microstructure of trabecular bone [127, 155]. This was also the result in Study I, where the trabecular bone parameters analysed from MSCT data showed weak correlations for many of the parameters despite high-dose protocols. The parameters were most often highly overestimated or underestimated and showed variations depending on which imaging protocol, reconstruction kernel or device used. In a study from another study-group it was shown that if a high-resolution and high-dose MSCT protocol of the calcaneus was used, it was possible to differentiate individuals with and without vertebral fractures [156]. It is also known that MSCT data in combination with the information of 
BMD from DXA improves the prediction of bone strength in vitro [157]. The MSCT technique, like the segmentation technique is evolving and future research may result in methods useful for trabecular bone microstructure imaging.

HR-pQCT is today often the method of choice for imaging in bone micro-structure research in vivo $[19,90,93,158-160]$. It is a high-resolution technique where the first-generation devices had voxels with sides down to $0.082 \mathrm{~mm}$. In Study III, we used a device with this resolution and got rather strong correlations (0.70-0.93) to micro-CT regarding all parameters, when segmenting using our in-house developed code. When segmenting using the software dedicated for the HR-pQCT data, the correlations were stronger (0.75-0.97), except for Tb.Tm where the correlations were weak. In the second-generation devices of HRpQCT, the isotropic voxels have sides of $0.061 \mathrm{~mm}$ [94]. One study demonstrated that the voxel size had effect on accuracy of the measurements of both trabecular and cortical microstructure [24] and like a more recent study showed that measurements of some of the bone structures could be more correctly depicted with smaller voxels [161]. Our in-house developed code overestimated BV/TV compared to when using the dedicated software. Both segmentation methods regardless showed results regarding the trabecular bone structure that were in the same range as other studies [24, 162]. A recent study, showed that results from the two HR-pQCT devices are comparable [163], and that is encouraging indicating that new studies can be compared to earlier executed ones. A major draw-back of HR-pQCT is that the technique is less wide-spread than MSCT and MRI devices. This is especially true in Sweden, where the first device was installed in Gothenburg in 2007 and still, to the best of my knowledge, is the only available device.

A more wide-spread high-resolution CT device is CBCT. The method is applicable for fluoroscopy of the intestines as well as for imaging of the skeleton. CBCT is often the method of choice in teeth, jaws and temporal bone imaging [164-166] [100, 103]. CBCTdevices are installed at University Hospitals and Dental Schools as well as in many private dental practices. The devices are often used only during day-time, opening possibilities for research during out-off office hours. The market of dental CBCT devices is expanding. There are devices for imaging in the sitting, standing as well as in the supine (lying down on the back) position [104]. Devices for imaging in the supine position can besides dental imaging also be used for examinations of the skeletal extremities, such as the wrist, heel and knee [108]. The devices differ in FOV imaging possibilities, tube current and voltage, rotation degree, pulsed or continuous x-ray emission. These factors have a high impact on the radiation dose $[120,121]$. Recently, devices more dedicated for the extremities have been developed and are installed in many hospitals. These CBCT devices offer 3D examinations of the extremities with an effective radiation dose much lower than that of MSCT [167]. The device is applicable also for imaging in the maxillofacial region with radiation doses comparable to dental CBCT [168].

During the research process, we have used CBCT devices from three manufacturers; J. Morita Mfg. Corp., Kyoto, Japan, QR, Verona, Italy and Planmed, Helsinki, Finland. The machines were chosen because they are available in many hospitals in Sweden and because of the differences in between them.

1. From the Morita Company, we have tested three devices, namely, 3D Accuitomo (image intensifier screen), 3D Accuitomo 80 and 3D Accuitomo 170 (flat panel 
detector). Those devices are for imaging patients in the sitting position and have the possibilities to manually change tube current, tube voltage, image voxel size, rotation degree as well as imaged field of view (FOV).

2. From QR, Verona we have tested two devices of NewTom 5G (installed in two different hospitals). In this scanner, for patients in the supine position, the tube current cannot be changed manually due to the automatic exposure control where the $\mathrm{mA}$ is based on patient size estimated from two scout images. The radiation emission is pulsated. FOV, image voxel size as well as radiation exposure time can be changed manually.

3. From Planmed, we have tested one Verity device dedicated for the extremities as well as for the maxillo-facial region. The image protocols installed in this device have several reconstruction kernels and filters as well as possibilities to choose imaged FOV. Imaging can be done with patients in sitting as well as in standing position.

Regarding the 3D Accuitomo 80 (the device at Linköping University hospital) we have tested eight different imaging protocols. The protocol most often used in our clinical practice, was run twice to test the reproducibility.

There are many CBCT studies analysing bone parameters in the mandibular region $[109,110$, 123, 169]. CBCT studies on human forearm specimens are sparse. In one study, the CBCT device NewTom 5G was used to image human radii specimens comparing the results with the HR-pQCT device XtremeCT [170]. The correlations regarding trabecular structures like Tb.N, Tb.Th and Tb.Sp were in that study $\geq 0.94$, demonstrating similarities in bone microstructure imaging between the devices. Porosities in the cortical part of the bones are known to impact bone strength [171] and such porosities as channels for nutrient arteries and other vascular porosities can be visualised in humans in vivo by HR-pQCT [172-174]. So far only one study has been published regarding CBCT and cortical porosities [170]. This research is of high interest for dental CBCT imaging, because mandibles besides the trabecular bone part also have portions of cortical bone, especially at the basis of the mandible. The specimens imaged in our four studies did include only small amounts of cortical bone and have so far not been part of our research. In future in vivo research of mandibles and radii, the cortical part may also be studied. Such research could be of even higher interest if CBCT devices in the future permits imaging of smaller voxels than those available on the market today.

Segmentation of CBCT data is challenging since the devices do not provide accurate greyscale values. Thus, the choice of segmentation method may have a strong impact on the results. Intensity thresholding, like Otsu [125], is known to be sensitive to the choice of thresholding [175]. This thresholding may have a greater effect when segmenting CBCT data compared to when segmenting micro-CT data. Not only because the grey-scale values are incorrect but also because the absence of valley between the two peaks (bone voxels and back-ground voxels). See the differences between the modalities in Fig. 11 as well as differences between the specimens in Fig. 15. 


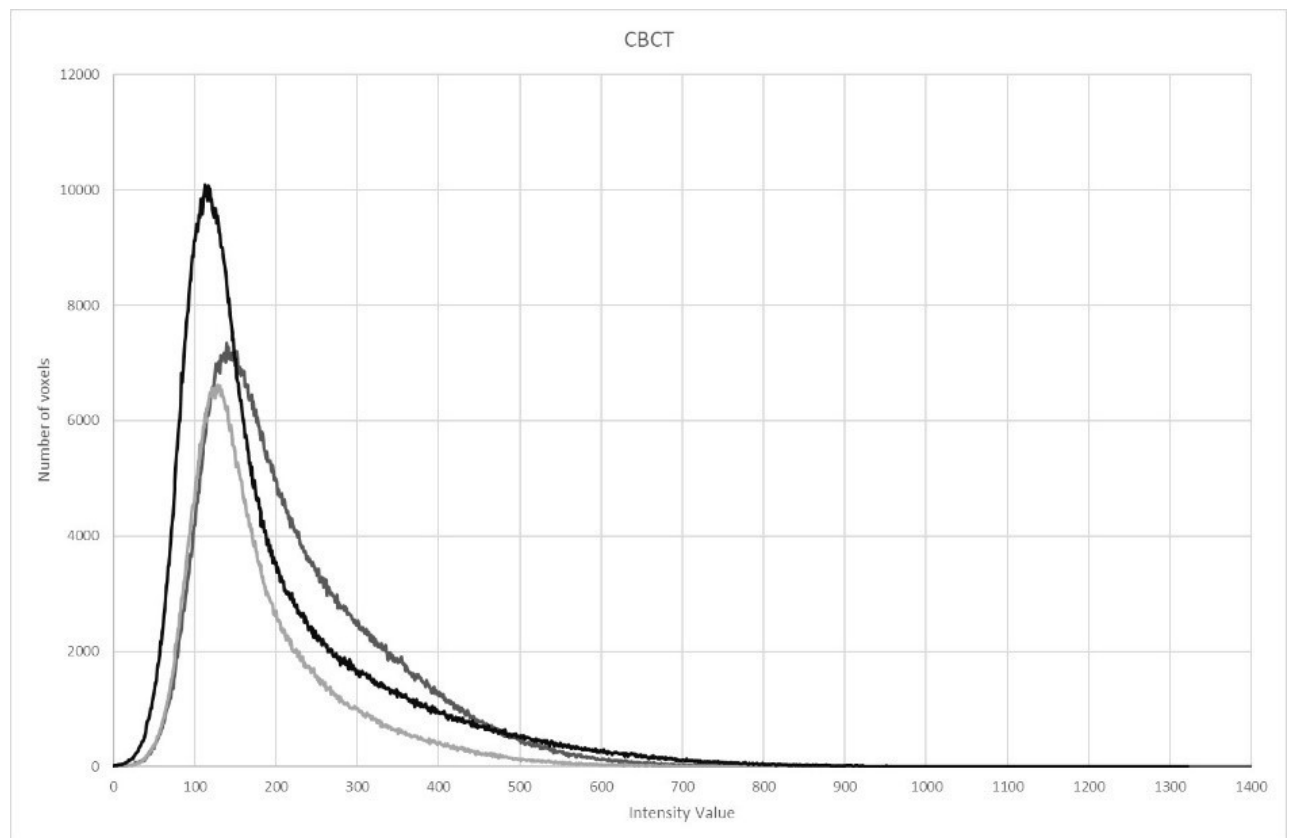

Figure 15. Histograms of three different bone specimens imaged by CBCT (3D Accuitomo 80) at $5 \mathrm{~mA}$ and $85 \mathrm{kV}, 80 \mu \mathrm{m}$ voxels and 360 degree rotation.

During our research project, we have evaluated different segmentation methods for the CBCT data. The segmentation software based on homogeneity thresholding origin from the automated 3D region growing (ARG) algorithm described in [126] has been developed in house. This segmentation method has so far showed the best results. In Table 2, previously not published results are shown, comparing intensity thresholding (Otsu) with homogeneity thresholding (ARG) of CBCT data from 15 radius bone specimens.

Table 2 Correlations with micro-CT

\begin{tabular}{|c|c|c|}
\hline Parameter $\backslash$ Segmentation & ARG & Otsu \\
\hline Tb.Sp & $0.85(0.58 ; 0.95)$ & $0.80(0.47 ; 0.93)$ \\
\hline Tb.Th & $\mathbf{0 . 9 6 ( 0 . 8 8 ; 0 . 9 9 )}$ & $0.60(0.10 ; 0.86)$ \\
\hline Tb.N & $\mathbf{0 . 9 5 ( 0 . 8 5 ; 0 . 9 8 )}$ & $\mathbf{0 . 9 2}(0.76 ; 0.97)$ \\
\hline BV/TV & $\mathbf{0 . 9 7 ( 0 . 9 1 ; 0 . 9 9 )}$ & $0.84(0.56 ; 0.95)$ \\
\hline Tb.Nd & $\mathbf{0 . 9 3 ( 0 . 7 9 ; 0 . 9 8 )}$ & $0.89(0.68 ; 0.96)$ \\
\hline Tb.Tm & $0.73(0.33 ; 0.91)$ & $0.71(0.29 ; 0.90)$ \\
\hline
\end{tabular}

Pearson correlation coefficients (r) with 95\% confidence interval. CBCT 3D Accuitomo 80. Imaging protocol at tube voltage at $85 \mathrm{kV}$, tube current at $8 \mathrm{~mA}, 80 \mu \mathrm{m}$ voxel size, a rotation degree of 360 and a FOV of $40 \mathrm{~mm}$. Bold figures denote values $\geq 0.90$.

The methods in our research project are based on binary (black and white) segmentation. This is a problem because most clinical CT devices have voxels with greater dimensions than the trabecular network. This results in partial volume effect, where many voxels become a mix of tissues, both bone and background. Many voxels will be regarded as bone although they only partly consist of bone. The segmentation results for trabecular bone parameters as well as for the estimations of the size and shape of the stiffness tensor will thus be negatively affected. 
This effect is clearly demonstrated in all four studies where the bone amount (BV/TV) is overestimated three to four times by all CBCT devices and more than four times by MSCT. This problem may be more accentuated in vivo, due to the risk for motion artefacts. One way to reduce the partial volume effect is to instead use direct calculations from the grey-scale images. To the best of our knowledge, this method is at present time only applicable for measurements of Tb.Th [176].

There are limitations linked to this research project. The perhaps most obvious limitation is that all CBCT devices overestimated the amount of bone compared to micro-CT, which affects the FEM-calculations of the trabecular bone biomechanical properties. Such overestimations may be overcome if the correlations to the reference method are strong and the degree of overestimation is known. Our studies indicate the importance of using the same CT device and to use the same segmentation methods in longitudinal studies. The fact that all studies have been carried out in vitro, impacts all results. Factors such as movement artefacts have therefore not been possible to analyse. This may be a strength, because knowing that the differences in the datasets depend on the different devices and imaging settings, allow more objective analyses and comparisons. Thus, allowing improvements of the segmentation code. In future clinical research, it is important to reduce the risk of patient movements. In CBCT devices for examinations in the sitting position careful and distinct information to the participants is vital. This in combination with stabile fixation of the head with straps and chin rest like in Fig. 9, is crucial. As an example, examinations of minute middle ear structures have been carried out with good results $[100,177,178]$ which is promising for future in vivo studies. For examinations of the wrist in this type of device it is necessary to construct a fixation device. This is one part of our ongoing projects. Another limitation is the limited number (fifteen and fourteen) of specimens. However, to reduce the effect of this limitation numerous examinations with differences in imaging protocols using three MSCT, one HRpQCT and five CBCT devices have been part of the projects. Numerous more data sets from the second generation of HR-pQCT is for the moment being analysed and will hopefully improve our segmentation methods.

Trabecular bone structure in the mandible has been studied to evaluate the possibilities of prediction of osteoporosis and osteoporotic fractures. The images used for this purpose have been $2 \mathrm{D}$ intraoral and panoramic images. The subjective visual assessment of those images was showing potential to identify individuals at risk for osteoporosis [179] and future fractures [180]. Also, semi-automatic methods for diagnosing skeletal osteoporosis by measuring the mandibular cortex width have been carried out showing promising results and high repeatability [181]. The combination of subjective visual assessment of mandibular bone sparse trabecular pattern and the web-based FRAX ${ }^{\circledR}$ tool has been shown to be able to predict major osteoporotic fractures in the same range as the combination of BMD and FRAX [182].

Results from earlier studies demonstrating possibilities to analyse both trabecular and cortical bone parameters, with strong correlations to osteoporotic fractures, are encouraging for future in vivo research. CBCT devices with possibilities for imaging of the extremities, make comparisons to research results from HR-pQCT devices possible. In $\boldsymbol{S t u d y} \boldsymbol{I}-\boldsymbol{I} \boldsymbol{V}$ is shown that 3D dental CBCTs' work well for subjective independent analyses of trabecular bone parameters in vitro. This in combination with the fact that trabecular as well as cortical bone 
most often is included in dental implant examinations in the mandible is also promising for future implant and osteoporosis studies in the maxillo-facial region. The device 3D Accuitomo, showed stronger correlations to micro-CT than the other studied devices, including MSCT, HR-pQCT and two other CBCT devices. Encouraging was that the Accuitomo worked well independent of imaging protocol and that the protocol most often used in our clinical practice showed strong correlations and low radiation dose. 


\section{Conclusions}

I. The moderate and image protocol dependent correlations between MSCT and micro-CT data for analysing trabecular bone structure parameters indicate that such analyses are currently challenging. On the other hand, the strong correlation between CBCT and micro-CT suggests the possibility of quantifying and monitoring trabecular bone microarchitecture changes over time in vivo, using CBCT.

II. Trabecular bone structure parameters can be quantified by clinical dental CBCT, in vitro, with strong correlations to the parameters obtained by micro-CT. There were only minor differences between the protocols regarding those correlations. The protocol using $80 \mu \mathrm{m}$ voxels was more affected than the $125 \mu \mathrm{m}$ voxel protocol when decreasing the scanning time to half, which resulted in weaker correlations, especially for trabecular separation, number and termini. Higher radiation dose protocols resulted in almost identical correlations compared to the protocol most often used in clinical practice at our institution, which had fair contrast-to-noise ratio (CNR), low radiation dose and strong correlations to microCT.

III. The strong correlations between micro-CT and the already clinically used device HR-pQCT regarding trabecular bone structure and for predicting stiffness and shear, using our in-house developed code, indicates that this code could be useful for segmenting HR-pQCT data. Also, the strong correlations between CBCT and micro-CT regarding the same parameters indicate that $\mathrm{CBCT}$ devices may be a feasible method for future clinical studies and osteoporosis research.

IV. Finite element-based calculations of biomechanics from CBCT data are feasible, with strong correlations for the scanner 3D Accuitomo 80. The two other CBCT scanners yielded good correlations, but not as strong as the Accuitomo. Although both stiffness and shear were overestimated, such measurements may be valuable for predicting dental implant survival by in vivo estimations of bone properties.

CBCT data of trabecular bone can be used for analysing trabecular bone properties, like bone microstructure and bone biomechanics, showing strong correlations to the reference method of micro-CT. The results depend on choice of CBCT device as well as on segmentation method. The in-house developed code, based on homogeneity thresholding using the ARG algorithm is appropriate for CBCT data despite that this device does not provide accurate grey-scale values. The bone volume fraction is overestimated compared to micro-CT, which must be considered when estimating bone properties in future clinical dental implant and osteoporosis research. 


\section{Future perspectives}

The possibilities of CBCT for estimating trabecular bone properties, like microstructure and biomechanics in clinical research is still to be evaluated.

Integration of the in-house developed software into digital picture archiving and communication (PACS) systems is needed to be able to analyse clinical data from more research centers in other countries as well as from more CBCT manufacturers.

One challenge is the impact the partial volume effect has on all estimations. Improvements of segmentation methods are crucial. Currently, more data captured by several imaging protocols from MSCT is being analysed using binary and grey-value based segmentation methods applying different kinds of image processing. Possibilities to more correctly identify the boundary between bone voxels and background will decrease the number of voxels consisting of both bone and background. The larger the voxel sizes the greater the impact of partial voxels. If segmentation of MSCT data can be improved, it will have even greater effect on the more high-resolution CBCT data.

Future possibilities include analyses of mandibular trabecular bone for osteoporosis research, studying the correlation of the mandibular bone structure and biomechanics to the structure of the wrist and DXA measurements. Following individuals over time, estimating the bone properties after medical treatment is another research possibility.

Future research may also include studies of the correlation of trabecular bone properties in the jaws and the correlation to dental implant primary stability and long-time survival. 


\section{References}

1. Standring S. Gray's anatomy : the anatomical basis of clinical practice. [Oxford]: Elsevier; 2016.

2. Clarke B. Normal bone anatomy and physiology. Clin J Am Soc Nephrol. 2008;3 Suppl 3:S131-9. doi: 10.2215/CJN.04151206. PubMed PMID: 18988698; PubMed Central PMCID: PMCPMC3152283.

3. Kleerekoper M, Villanueva AR, Stanciu J, Rao DS, Parfitt AM. The Role of 3-Dimensional Trabecular Microstructure in the Pathogenesis of Vertebral Compression Fractures. Calcified tissue international. 1985;37(6):594-7. doi: 10.1007/bf02554913. PubMed PMID: WOS:A1985AVS2700006.

4. Augat $P$, Schorlemmer $S$. The role of cortical bone and its microstructure in bone strength. Age Ageing. 2006;35 Suppl 2:ii27-ii31. doi: 10.1093/ageing/afl081. PubMed PMID: 16926200.

5. Banijamali SM, Oftadeh R, Nazarian A, Goebel R, Vaziri A, Nayeb-Hashemi H. Effects of different loading patterns on the trabecular bone morphology of the proximal femur using adaptive bone remodeling. J Biomech Eng. 2015;137(1). doi: 10.1115/1.4029059. PubMed PMID: 25392856.

6. Turner $\mathrm{CH}$. Biomechanics of bone: determinants of skeletal fragility and bone quality. Osteoporosis international : a journal established as result of cooperation between the European Foundation for Osteoporosis and the National Osteoporosis Foundation of the USA. 2002;13(2):97-104. doi: 10.1007/s001980200000. PubMed PMID: 11905527.

7. Hadjidakis DJ, Androulakis, II. Bone remodeling. Annals of the New York Academy of Sciences. 2006;1092:385-96. doi: 10.1196/annals.1365.035. PubMed PMID: 17308163.

8. Parfitt AM. Recent developments in bone physiology. Henry Ford Hosp Med J. 1983;31(4):20910. PubMed PMID: 6674264.

9. Seeman E, Delmas PD. Bone quality--the material and structural basis of bone strength and fragility. N Engl J Med. 2006;354(21):2250-61. doi: 10.1056/NEJMra053077. PubMed PMID: 16723616.

10. Bonewald LF. The amazing osteocyte. Journal of bone and mineral research : the official journal of the American Society for Bone and Mineral Research. 2011;26(2):229-38. doi: 10.1002/jbmr.320. PubMed PMID: 21254230; PubMed Central PMCID: PMCPMC3179345.

11. Zebaze R, Seeman E. Cortical bone: a challenging geography. Journal of bone and mineral research : the official journal of the American Society for Bone and Mineral Research. 2015;30(1):24-9. doi: 10.1002/jbmr.2419. PubMed PMID: 25431247.

12. Franz-Odendaal TA, Hall BK, Witten PE. Buried alive: how osteoblasts become osteocytes. Dev Dyn. 2006;235(1):176-90. doi: 10.1002/dvdy.20603. PubMed PMID: 16258960.

13. Frost HM. In vivo osteocyte death. The Journal of bone and joint surgery American volume. 1960;42-A:138-43. PubMed PMID: 13849861.

14. Parfitt A. Bone-forming cells in Clinical Conditions. Boca Raton, Fl: Telford Press and CRC Press; 1990.

15. Dallas SL, Prideaux M, Bonewald LF. The osteocyte: an endocrine cell ... and more. Endocr Rev. 2013;34(5):658-90. doi: 10.1210/er.2012-1026. PubMed PMID: 23612223; PubMed Central PMCID: PMCPMC3785641.

16. Jilka RL, O'Brien CA, Roberson PK, Bonewald LF, Weinstein RS, Manolagas SC. Dysapoptosis of osteoblasts and osteocytes increases cancellous bone formation but exaggerates cortical porosity with age. Journal of bone and mineral research : the official journal of the American 
Society for Bone and Mineral Research. 2014;29(1):103-17. doi: 10.1002/jbmr.2007. PubMed PMID: 23761243; PubMed Central PMCID: PMCPMC3823639.

17. Tjong W, Nirody J, Burghardt AJ, Carballido-Gamio J, Kazakia GJ. Structural analysis of cortical porosity applied to HR-pQCT data. Medical physics. 2014;41(1):013701. doi: 10.1118/1.4851575. PubMed PMID: 24387533; PubMed Central PMCID: PMCPMC3895089.

18. Basillais A, Bensamoun S, Chappard C, Brunet-Imbault B, Lemineur G, Ilharreborde B, et al. Three-dimensional characterization of cortical bone microstructure by microcomputed tomography: validation with ultrasonic and microscopic measurements. J Orthop Sci. 2007;12(2):141-8. doi: 10.1007/s00776-006-1104-z. PubMed PMID: 17393269.

19. Sundh D, Mellstrom D, Nilsson M, Karlsson M, Ohlsson C, Lorentzon M. Increased Cortical Porosity in Older Men With Fracture. Journal of bone and mineral research : the official journal of the American Society for Bone and Mineral Research. 2015;30(9):1692-700. doi: 10.1002/jbmr.2509. PubMed PMID: 25777580.

20. Nazarian A, Christiansen BA. Trabecular bone: light as a feather, stiff as a board. J Biomech Eng. 2015;137(1). doi: 10.1115/1.4029167. PubMed PMID: 25408309.

21. Thomsen JS, Laib A, Koller B, Prohaska S, Mosekilde L, Gowin W. Stereological measures of trabecular bone structure: comparison of 3D micro computed tomography with $2 \mathrm{D}$ histological sections in human proximal tibial bone biopsies. J Microsc-Oxf. 2005;218:171-9. doi: 10.1111/j.1365-2818.2005.01469.x. PubMed PMID: WOS:000228721000009.

22. Parfitt AM, Drezner MK, Glorieux FH, Kanis JA, Malluche H, Meunier PJ, et al. Bone Histomorphometry - Standardization of Nomenclature, Symbols, and Units. J Bone Miner Res. 1987;2(6):595-610. PubMed PMID: WOS:A1987L307300014.

23. Bouxsein ML, Boyd SK, Christiansen BA, Guldberg RE, Jepsen KJ, Muller R. Guidelines for assessment of bone microstructure in rodents using micro-computed tomography. Journal of bone and mineral research : the official journal of the American Society for Bone and Mineral Research. 2010;25(7):1468-86. doi: 10.1002/jbmr.141. PubMed PMID: 20533309.

24. Tjong W, Kazakia GJ, Burghardt AJ, Majumdar S. The effect of voxel size on high-resolution peripheral computed tomography measurements of trabecular and cortical bone microstructure. Medical physics. 2012;39(4):1893-903. doi: 10.1118/1.3689813. PubMed PMID: 22482611; PubMed Central PMCID: PMC3316694.

25. Kazakia GJ, Burghardt AJ, Link TM, Majumdar S. Variations in morphological and biomechanical indices at the distal radius in subjects with identical BMD. Journal of biomechanics. 2011;44(2):257-66. doi: 10.1016/j.jbiomech.2010.10.010. PubMed PMID: 21071031; PubMed Central PMCID: PMC3019283.

26. Albrektsson T, Branemark PI, Hansson HA, Lindstrom J. Osseointegrated titanium implants. Requirements for ensuring a long-lasting, direct bone-to-implant anchorage in man. Acta Orthop Scand. 1981;52(2):155-70. PubMed PMID: 7246093.

27. Sakka S, Coulthard P. Bone quality: a reality for the process of osseointegration. Implant dentistry. 2009;18(6):480-5. doi: 10.1097/ID.0b013e3181bb840d. PubMed PMID: 20009601.

28. Turkyilmaz I, Tozum TF, Tumer C, Ozbek EN. Assessment of correlation between computerized tomography values of the bone, and maximum torque and resonance frequency values at dental implant placement. J Oral Rehabil. 2006;33(12):881-8. doi: 10.1111/j.13652842.2006.01692.x. PubMed PMID: 17168930.

29. Strub JR, Jurdzik BA, Tuna T. Prognosis of immediately loaded implants and their restorations: a systematic literature review. J Oral Rehabil. 2012;39(9):704-17. doi: 10.1111/j.13652842.2012.02315.x. PubMed PMID: 22607161. 
30. Merheb J, Temmerman A, Rasmusson L, Kubler A, Thor A, Quirynen M. Influence of Skeletal and Local Bone Density on Dental Implant Stability in Patients with Osteoporosis. Clinical implant dentistry and related research. 2016;18(2):253-60. doi: 10.1111/cid.12290. PubMed PMID: 26864614.

31. Javed F, Ahmed HB, Crespi R, Romanos GE. Role of primary stability for successful osseointegration of dental implants: Factors of influence and evaluation. Interv Med Appl Sci. 2013;5(4):162-7. doi: 10.1556/IMAS.5.2013.4.3. PubMed PMID: 24381734; PubMed Central PMCID: PMCPMC3873594.

32. Javed F, Romanos GE. The role of primary stability for successful immediate loading of dental implants. A literature review. J Dent. 2010;38(8):612-20. doi: 10.1016/j.jdent.2010.05.013. PubMed PMID: 20546821.

33. Ottoni JM, Oliveira ZF, Mansini R, Cabral AM. Correlation between placement torque and survival of single-tooth implants. The International journal of oral \& maxillofacial implants. 2005;20(5):769-76. PubMed PMID: 16274152.

34. Benavides E, Rios HF, Ganz SD, An CH, Resnik R, Reardon GT, et al. Use of cone beam computed tomography in implant dentistry: the International Congress of Oral Implantologists consensus report. Implant dentistry. 2012;21(2):78-86. doi: 10.1097/ID.0b013e31824885b5. PubMed PMID: 22382748.

35. Tsutsumi K, Chikui T, Okamura K, Yoshiura K. Accuracy of linear measurement and the measurement limits of thin objects with cone beam computed tomography: effects of measurement directions and of phantom locations in the fields of view. The International journal of oral \& maxillofacial implants. 2011;26(1):91-100. PubMed PMID: 21365043.

36. Lofthag-Hansen S, Grondahl K, Ekestubbe A. Cone-beam CT for preoperative implant planning in the posterior mandible: visibility of anatomic landmarks. Clinical implant dentistry and related research. 2009;11(3):246-55. doi: 10.1111/j.1708-8208.2008.00114.x. PubMed PMID: 18783419.

37. Pauwels R, Jacobs R, Singer SR, Mupparapu M. CBCT-based bone quality assessment: are Hounsfield units applicable? Dento maxillo facial radiology. 2015;44(1):20140238. doi: 10.1259/dmfr.20140238. PubMed PMID: 25315442; PubMed Central PMCID: PMCPMC4277442.

38. Nackaerts O, Maes F, Yan H, Souza PC, Pauwels R, Jacobs R. Analysis of intensity variability in multislice and cone beam computed tomography. Clinical oral implants research.

2011;22(8):873-9. doi: 10.1111/j.1600-0501.2010.02076.x. PubMed PMID: WOS:000292605600013.

39. Oliveira ML, Tosoni GM, Lindsey DH, Mendoza K, Tetradis S, Mallya SM. Influence of anatomical location on $\mathrm{CT}$ numbers in cone beam computed tomography. Oral surgery, oral medicine, oral pathology and oral radiology. 2013;115(4):558-64. doi: 10.1016/j.000o.2013.01.021. PubMed PMID: 23522649.

40. Bailey DA, Martin AD, McKay HA, Whiting S, Mirwald R. Calcium accretion in girls and boys during puberty: a longitudinal analysis. Journal of bone and mineral research : the official journal of the American Society for Bone and Mineral Research. 2000;15(11):2245-50. doi: 10.1359/jbmr.2000.15.11.2245. PubMed PMID: 11092406.

41. Farr JN, Khosla S, Miyabara Y, Miller VM, Kearns AE. Effects of estrogen with micronized progesterone on cortical and trabecular bone mass and microstructure in recently postmenopausal women. The Journal of clinical endocrinology and metabolism. 2013;98(2):E249-57. doi: 10.1210/jc.2012-3406. PubMed PMID: 23322818; PubMed Central PMCID: PMCPMC3565106. 
42. Khosla S, Pacifici R. Chapter 46 - Estrogen Deficiency, Postmenopausal Osteoporosis, and AgeRelated Bone Loss A2 - Marcus, Robert. In: Feldman D, Dempster DW, Luckey M, Cauley JA, editors. Osteoporosis (Fourth Edition). San Diego: Academic Press; 2013. p. 1113-36.

43. Hannan MT, Felson DT, Dawson-Hughes B, Tucker KL, Cupples LA, Wilson PW, et al. Risk factors for longitudinal bone loss in elderly men and women: the Framingham Osteoporosis Study. Journal of bone and mineral research : the official journal of the American Society for Bone and Mineral Research. 2000;15(4):710-20. doi: 10.1359/jbmr.2000.15.4.710. PubMed PMID: 10780863.

44. Lorentzon M, Mellstrom D, Haug E, Ohlsson C. Smoking is associated with lower bone mineral density and reduced cortical thickness in young men. The Journal of clinical endocrinology and metabolism. 2007;92(2):497-503. doi: 10.1210/jc.2006-1294. PubMed PMID: 17077132.

45. Weaver CM, Gordon CM, Janz KF, Kalkwarf HJ, Lappe JM, Lewis R, et al. The National Osteoporosis Foundation's position statement on peak bone mass development and lifestyle factors: a systematic review and implementation recommendations. Osteoporosis international : a journal established as result of cooperation between the European Foundation for Osteoporosis and the National Osteoporosis Foundation of the USA. 2016;27(4):1281-386. doi: 10.1007/s00198-015-3440-3. PubMed PMID: 26856587; PubMed Central PMCID: PMCPMC4791473.

46. Liu-Ambrose TY, Khan KM, Eng JJ, Heinonen A, McKay HA. Both resistance and agility training increase cortical bone density in 75- to 85-year-old women with low bone mass: a 6-month randomized controlled trial. Journal of clinical densitometry : the official journal of the International Society for Clinical Densitometry. 2004;7(4):390-8. PubMed PMID: 15618599.

47. Nih Consensus Development Panel on Osteoporosis Prevention D, Therapy. Osteoporosis prevention, diagnosis, and therapy. JAMA. 2001;285(6):785-95. PubMed PMID: 11176917.

48. Warburton DE, Glendhill N, Quinney A. The effects of changes in musculoskeletal fitness on health. Can J Appl Physiol. 2001;26(2):161-216. PubMed PMID: 11312416.

49. Cullum ID, Ell PJ, Ryder JP. X-ray dual-photon absorptiometry: a new method for the measurement of bone density. The British journal of radiology. 1989;62(739):587-92. Epub 1989/07/01. PubMed PMID: 2758245.

50. Bauer JS, Link TM. Advances in osteoporosis imaging. European journal of radiology. 2009;71(3):440-9. doi: 10.1016/j.ejrad.2008.04.064. PubMed PMID: 19651482.

51. Miller PD, Siris ES, Barrett-Connor E, Faulkner KG, Wehren LE, Abbott TA, et al. Prediction of fracture risk in postmenopausal white women with peripheral bone densitometry: evidence from the National Osteoporosis Risk Assessment. Journal of bone and mineral research : the official journal of the American Society for Bone and Mineral Research. 2002;17(12):2222-30. doi: 10.1359/jbmr.2002.17.12.2222. PubMed PMID: 12469916.

52. Assessment of fracture risk and its application to screening for postmenopausal osteoporosis. Report of a WHO Study Group. World Health Organ Tech Rep Ser. 1994;843:1-129. PubMed PMID: 7941614.

53. Kanis JA, Gluer CC. An update on the diagnosis and assessment of osteoporosis with densitometry. Committee of Scientific Advisors, International Osteoporosis Foundation. Osteoporosis international : a journal established as result of cooperation between the European Foundation for Osteoporosis and the National Osteoporosis Foundation of the USA. 2000;11(3):192-202. PubMed PMID: 10824234. 
54. Raisz LG. Pathogenesis of osteoporosis: concepts, conflicts, and prospects. J Clin Invest. 2005;115(12):3318-25. doi: 10.1172/JCI27071. PubMed PMID: 16322775; PubMed Central PMCID: PMCPMC1297264.

55. SBU. Osteoporos - prevention, diagnostik och behandling 2003. SBU (The Swedish Council of Technology Assessment in Health Care). 2003.

56. Kanis JA, Oden A, McCloskey EV, Johansson H, WahI DA, Cooper C, et al. A systematic review of hip fracture incidence and probability of fracture worldwide. Osteoporosis international : a journal established as result of cooperation between the European Foundation for Osteoporosis and the National Osteoporosis Foundation of the USA. 2012;23(9):2239-56. doi: 10.1007/s00198-012-1964-3. PubMed PMID: 22419370; PubMed Central PMCID: PMC3421108.

57. Jarvinen TL, Michaelsson K, Aspenberg P, Sievanen H. Osteoporosis: the emperor has no clothes. Journal of internal medicine. 2015;277(6):662-73. doi: 10.1111/joim.12366. PubMed PMID: 25809279; PubMed Central PMCID: PMC4497616.

58. Kanis JA, Johnell O, Oden A, Jonsson B, De Laet C, Dawson A. Risk of hip fracture according to the World Health Organization criteria for osteopenia and osteoporosis. Bone. 2000;27(5):585-90. PubMed PMID: 11062343.

59. Kanis JA, Johnell O, Oden A, Johansson H, McCloskey E. FRAX and the assessment of fracture probability in men and women from the UK. Osteoporosis international : a journal established as result of cooperation between the European Foundation for Osteoporosis and the National Osteoporosis Foundation of the USA. 2008;19(4):385-97. doi: 10.1007/s00198-007-0543-5. PubMed PMID: 18292978; PubMed Central PMCID: PMCPMC2267485.

60. Stehman-Breen CO, Sherrard DJ, Alem AM, Gillen DL, Heckbert SR, Wong CS, et al. Risk factors for hip fracture among patients with end-stage renal disease. Kidney Int. 2000;58(5):2200-5. doi: 10.1111/j.1523-1755.2000.00394.x. PubMed PMID: 11044242.

61. Gal-Moscovici A, Sprague SM. Osteoporosis and chronic kidney disease. Semin Dial. 2007;20(5):423-30. doi: 10.1111/j.1525-139X.2007.00319.x. PubMed PMID: 17897249.

62. Kanis JA, Oden A, Johansson H, Borgstrom F, Strom O, McCloskey E. FRAX and its applications to clinical practice. Bone. 2009;44(5):734-43. doi: 10.1016/j.bone.2009.01.373. PubMed PMID: 19195497.

63. Cody DD, Gross GJ, Hou FJ, Spencer HJ, Goldstein SA, Fyhrie DP. Femoral strength is better predicted by finite element models than QCT and DXA. Journal of biomechanics. 1999;32(10):1013-20. PubMed PMID: 10476839.

64. Link TM, Vieth V, Langenberg R, Meier N, Lotter A, Newitt D, et al. Structure analysis of high resolution magnetic resonance imaging of the proximal femur: in vitro correlation with biomechanical strength and BMD. Calcified tissue international. 2003;72(2):156-65. doi: 10.1007/s00223-001-2132-5. PubMed PMID: 12370799.

65. Ulrich D, van Rietbergen B, Laib A, Ruegsegger P. The ability of three-dimensional structural indices to reflect mechanical aspects of trabecular bone. Bone. 1999;25(1):55-60. doi: 10.1016/s8756-3282(99)00098-8. PubMed PMID: 10423022.

66. Rudang R, Darelid A, Nilsson M, Mellstrom D, Ohlsson C, Lorentzon M. X-ray-verified fractures are associated with finite element analysis-derived bone strength and trabecular microstructure in young adult men. Journal of bone and mineral research : the official journal of the American Society for Bone and Mineral Research. 2013;28(11):2305-16. doi: 10.1002/jbmr.1974. PubMed PMID: 23658040. 
67. Johnell O, Kanis JA, Oden A, Johansson H, De Laet C, Delmas P, et al. Predictive value of BMD for hip and other fractures. Journal of bone and mineral research : the official journal of the American Society for Bone and Mineral Research. 2005;20(7):1185-94. doi: 10.1359/JBMR.050304. PubMed PMID: 15940371.

68. Siris ES, Adler R, Bilezikian J, Bolognese M, Dawson-Hughes B, Favus MJ, et al. The clinical diagnosis of osteoporosis: a position statement from the National Bone Health Alliance Working Group. Osteoporosis international : a journal established as result of cooperation between the European Foundation for Osteoporosis and the National Osteoporosis Foundation of the USA. 2014;25(5):1439-43. doi: 10.1007/s00198-014-2655-z. PubMed PMID: 24577348; PubMed Central PMCID: PMCPMC3988515.

69. Carter DR, Bouxsein ML, Marcus R. New approaches for interpreting projected bone densitometry data. Journal of bone and mineral research : the official journal of the American Society for Bone and Mineral Research. 1992;7(2):137-45. doi: 10.1002/jbmr.5650070204. PubMed PMID: 1570758.

70. Chun KJ. Bone densitometry. Semin Nucl Med. 2011;41(3):220-8. doi: 10.1053/j.semnuclmed.2010.12.002. PubMed PMID: 21440697.

71. Blake GM, Fogelman I. How important are BMD accuracy errors for the clinical interpretation of DXA scans? Journal of bone and mineral research : the official journal of the American Society for Bone and Mineral Research. 2008;23(4):457-62. doi: 10.1359/jbmr.071119. PubMed PMID: 18052754.

72. Silva BC, Leslie WD, Resch H, Lamy O, Lesnyak O, Binkley N, et al. Trabecular bone score: a noninvasive analytical method based upon the DXA image. Journal of bone and mineral research : the official journal of the American Society for Bone and Mineral Research. 2014;29(3):518-30. doi: 10.1002/jbmr.2176. PubMed PMID: 24443324.

73. Maquer G, Lu Y, Dall'Ara E, Chevalier Y, Krause M, Yang L, et al. The Initial Slope of the Variogram, Foundation of the Trabecular Bone Score, Is Not or Poorly Associated With Vertebral Strength. Journal of bone and mineral research : the official journal of the American Society for Bone and Mineral Research. 2015. doi: 10.1002/jbmr.2610. PubMed PMID: 26234619.

74. Maquer G, Musy SN, Wandel J, Gross T, Zysset PK. Bone volume fraction and fabric anisotropy are better determinants of trabecular bone stiffness than other morphological variables. Journal of bone and mineral research : the official journal of the American Society for Bone and Mineral Research. 2015;30(6):1000-8. doi: 10.1002/jbmr.2437. PubMed PMID: 25529534.

75. Cummings SR, Nevitt MC, Browner WS, Stone K, Fox KM, Ensrud KE, et al. Risk factors for hip fracture in white women. Study of Osteoporotic Fractures Research Group. N Engl J Med. 1995;332(12):767-73. doi: 10.1056/NEJM199503233321202. PubMed PMID: 7862179.

76. Blake GM, Naeem M, Boutros M. Comparison of effective dose to children and adults from dual X-ray absorptiometry examinations. Bone. 2006;38(6):935-42. doi: 10.1016/j.bone.2005.11.007. PubMed PMID: 16376161.

77. Griffith JF, Genant HK. Bone mass and architecture determination: state of the art. Best practice \& research Clinical endocrinology \& metabolism. 2008;22(5):737-64. doi: 10.1016/j.beem.2008.07.003. PubMed PMID: 19028355.

78. Hounsfield GN. The E.M.I. scanner. Proc R Soc Lond B Biol Sci. 1977;195(1119):281-9. PubMed PMID: 13396.

79. Diederichs G, Link TM, Kentenich M, Schwieger K, Huber MB, Burghardt AJ, et al. Assessment of trabecular bone structure of the calcaneus using multi-detector $\mathrm{CT}$ : Correlation with 
microCT and biomechanical testing. Bone. 2009;44(5):976-83. doi:

10.1016/j.bone.2009.01.372. PubMed PMID: WOS:000265436000034.

80. Bauer JS, Link TM, Burghardt A, Henning TD, Mueller D, Majumdar S, et al. Analysis of trabecular bone structure with multidetector spiral computed tomography in a simulated softtissue environment. Calcified tissue international. 2007;80(6):366-73. doi: 10.1007/s00223007-9021-5. PubMed PMID: WOS:000247412700004.

81. Issever AS, Link TM, Kentenich M, Rogalla P, Burghardt AJ, Kazakia GJ, et al. Assessment of trabecular bone structure using MDCT: comparison of 64-and 320-slice CT using HR-pQCT as the reference standard. European Radiology. 2010;20(2):458-68. doi: 10.1007/s00330-0091571-7. PubMed PMID: WOS:000274109700022.

82. McCollough CH, Bushberg JT, Fletcher JG, Eckel LJ. Answers to Common Questions About the Use and Safety of CT Scans. Mayo Clin Proc. 2015;90(10):1380-92. doi: 10.1016/j.mayocp.2015.07.011. PubMed PMID: 26434964.

83. Alshamari M, Geijer M, Norrman E, Geijer H. Low-dose computed tomography of the lumbar spine: a phantom study on imaging parameters and image quality. Acta radiologica. 2014;55(7):824-32. doi: 10.1177/0284185113509615. PubMed PMID: 24215904.

84. Kalra MK, Woisetschlager M, Dahlstrom N, Singh S, Digumarthy S, Do S, et al. Sinogramaffirmed iterative reconstruction of low-dose chest CT: effect on image quality and radiation dose. AJR Am J Roentgenol. 2013;201(2):W235-44. doi: 10.2214/AJR.12.9569. PubMed PMID: 23883238.

85. Sievanen H, Koskue V, Rauhio A, Kannus P, Heinonen A, Vuori I. Peripheral quantitative computed tomography in human long bones: evaluation of in vitro and in vivo precision. Journal of bone and mineral research : the official journal of the American Society for Bone and Mineral Research. 1998;13(5):871-82. doi: 10.1359/jbmr.1998.13.5.871. PubMed PMID: 9610752.

86. Laib A, Rüegsegger P. Calibration of trabecular bone structure measurements of in vivo threedimensional peripheral quantitative computed tomography with $28-\mu \mathrm{m}$-resolution microcomputed tomography. Bone. 1999;24(1):35-9.

87. MacNeil JA, Boyd SK. Accuracy of high-resolution peripheral quantitative computed tomography for measurement of bone quality. Medical engineering \& physics. 2007;29(10):1096-105. doi: 10.1016/j.medengphy.2006.11.002. PubMed PMID: 17229586.

88. Burrows M, Liu D, Perdios A, Moore S, Mulpuri K, McKay H. Assessing bone microstructure at the distal radius in children and adolescents using HR-pQCT: a methodological pilot study. Journal of clinical densitometry : the official journal of the International Society for Clinical Densitometry. 2010;13(4):451-5. doi: 10.1016/j.jocd.2010.02.003. PubMed PMID: 20663697.

89. Burrows M, Liu D, McKay H. High-resolution peripheral QCT imaging of bone micro-structure in adolescents. Osteoporosis international : a journal established as result of cooperation between the European Foundation for Osteoporosis and the National Osteoporosis Foundation of the USA. 2010;21(3):515-20. doi: 10.1007/s00198-009-0913-2. PubMed PMID: 19322507.

90. Boutroy S, Bouxsein ML, Munoz F, Delmas PD. In vivo assessment of trabecular bone microarchitecture by high-resolution peripheral quantitative computed tomography. The Journal of clinical endocrinology and metabolism. 2005;90(12):6508-15. doi: 10.1210/jc.20051258. PubMed PMID: 16189253.

91. Liu XS, Cohen A, Shane E, Stein E, Rogers H, Kokolus SL, et al. Individual trabeculae segmentation (ITS)-based morphological analysis of high-resolution peripheral quantitative 
computed tomography images detects abnormal trabecular plate and rod microarchitecture in premenopausal women with idiopathic osteoporosis. Journal of bone and mineral research : the official journal of the American Society for Bone and Mineral Research. 2010;25(7):1496505. doi: 10.1002/jbmr.50. PubMed PMID: 20200967; PubMed Central PMCID: PMC3131618.

92. Boutry N, Cortet B, Chappard D, Dubois P, Demondion X, Marchandise X, et al. Bone structure of the calcaneus: analysis with magnetic resonance imaging and correlation with histomorphometric study. Osteoporosis international : a journal established as result of cooperation between the European Foundation for Osteoporosis and the National Osteoporosis Foundation of the USA. 2004;15(10):827-33. doi: 10.1007/s00198-004-1619-0. PubMed PMID: 15042283.

93. Burghardt AJ, Pialat JB, Kazakia GJ, Boutroy S, Engelke K, Patsch JM, et al. Multicenter precision of cortical and trabecular bone quality measures assessed by high-resolution peripheral quantitative computed tomography. Journal of bone and mineral research : the official journal of the American Society for Bone and Mineral Research. 2013;28(3):524-36. doi: 10.1002/jbmr.1795. PubMed PMID: 23074145; PubMed Central PMCID: PMC3577969.

94. Hosseini HS, Maquer G, Zysset PK. muCT-based trabecular anisotropy can be reproducibly computed from HR-pQCT scans using the triangulated bone surface. Bone. 2017;97:114-20. doi: 10.1016/j.bone.2017.01.016. PubMed PMID: 28109918.

95. Elliott JC, Dover SD. X-ray microtomography. J Microsc. 1982;126(Pt 2):211-3. PubMed PMID: 7086891.

96. Ford NL, Thornton MM, Holdsworth DW. Fundamental image quality limits for microcomputed tomography in small animals. Medical physics. 2003;30(11):2869-77. doi: 10.1118/1.1617353. PubMed PMID: 14655933.

97. Arai Y, Tammisalo E, Iwai K, Hashimoto K, Shinoda K. Development of a compact computed tomographic apparatus for dental use. Dento maxillo facial radiology. 1999;28(4):245-8. Epub 1999/08/24. doi: 10.1038/sj/dmfr/4600448. PubMed PMID: 10455389.

98. Lofthag-Hansen S, Huumonen S, Grondahl K, Grondahl HG. Limited cone-beam CT and intraoral radiography for the diagnosis of periapical pathology. Oral surgery, oral medicine, oral pathology, oral radiology, and endodontics. 2007;103(1):114-9. doi: 10.1016/j.tripleo.2006.01.001. PubMed PMID: 17178504.

99. Miracle AC, Mukherji SK. Conebeam CT of the head and neck, part 2: clinical applications. AJNR American journal of neuroradiology. 2009;30(7):1285-92. doi: 10.3174/ajnr.A1654. PubMed PMID: 19461061.

100. Peltonen LI, Aarnisalo AA, Kortesniemi MK, Suomalainen A, Jero J, Robinson S. Limited conebeam computed tomography imaging of the middle ear: a comparison with multislice helical computed tomography. Acta radiologica. 2007;48(2):207-12. doi: 10.1080/02841850601080465. PubMed PMID: 17354143.

101. Hussain AM, Packota G, Major PW, Flores-Mir C. Role of different imaging modalities in assessment of temporomandibular joint erosions and osteophytes: a systematic review. Dento maxillo facial radiology. 2008;37(2):63-71. doi: 10.1259/dmfr/16932758. PubMed PMID: 18239033.

102. Lund H, Grondahl K, Hansen K, Grondahl HG. Apical root resorption during orthodontic treatment. A prospective study using cone beam CT. The Angle orthodontist. 2012;82(3):4807. doi: 10.2319/061311-390.1. PubMed PMID: 21919826.

103. Scarfe WC, Farman AG, Sukovic P. Clinical applications of cone-beam computed tomography in dental practice. Journal. 2006;72(1):75-80. PubMed PMID: 16480609. 
104. Nemtoi A, Czink C, Haba D, Gahleitner A. Cone beam CT: a current overview of devices. Dento maxillo facial radiology. 2013;42(8):20120443. doi: 10.1259/dmfr.20120443. PubMed PMID: 23818529; PubMed Central PMCID: PMC3922261.

105. Miracle AC, Mukherji SK. Conebeam CT of the head and neck, part 1: physical principles. AJNR American journal of neuroradiology. 2009;30(6):1088-95. doi: 10.3174/ajnr.A1653. PubMed PMID: 19439484.

106. Koskinen SK, Haapamaki VV, Salo J, Lindfors NC, Kortesniemi M, Seppala L, et al. CT arthrography of the wrist using a novel, mobile, dedicated extremity cone-beam CT (CBCT). Skeletal radiology. 2013;42(5):649-57. doi: 10.1007/s00256-012-1516-0. PubMed PMID: 22990597.

107. Faccioli N, Foti G, Barillari M, Atzei A, Mucelli RP. Finger fractures imaging: accuracy of conebeam computed tomography and multislice computed tomography. Skeletal radiology. 2010;39(11):1087-95. doi: 10.1007/s00256-010-0911-7. PubMed PMID: 20224906.

108. De Cock J, Mermuys K, Goubau J, Van Petegem S, Houthoofd B, Casselman JW. Cone-beam computed tomography: a new low dose, high resolution imaging technique of the wrist, presentation of three cases with technique. Skeletal radiology. 2012;41(1):93-6. doi: 10.1007/s00256-011-1198-z. PubMed PMID: 21603872.

109. Hua Y, Nackaerts O, Duyck J, Maes F, Jacobs R. Bone quality assessment based on cone beam computed tomography imaging. Clinical oral implants research. 2009;20(8):767-71. doi: 10.1111/j.1600-0501.2008.01677.x. PubMed PMID: WOS:0002677433300004.

110. Van Dessel J, Nicolielo LF, Huang Y, Coudyzer W, Salmon B, Lambrichts I, et al. Accuracy and reliability of different cone beam computed tomography (CBCT) devices for structural analysis of alveolar bone in comparison with multislice CT and micro-CT. Eur J Oral Implantol. 2017;10(1):95-105. PubMed PMID: 28327698.

111. Van Dessel J, Huang Y, Depypere M, Rubira-Bullen I, Maes F, Jacobs R. A comparative evaluation of cone beam CT and micro-CT on trabecular bone structures in the human mandible. Dento maxillo facial radiology. 2013;42(8):20130145. doi: 10.1259/dmfr.20130145. PubMed PMID: 23833320.

112. Hohlweg-Majert B, Metzger MC, Kummer T, Schulze D. Morphometric analysis - Cone beam computed tomography to predict bone quality and quantity. Journal of Cranio-Maxillofacial Surgery. 2011;39(5):330-4. doi: 10.1016/j.jcms.2010.10.002. PubMed PMID: WOS:000292786400005.

113. Ho JT, Wu J, Huang HL, Chen MY, Fuh LJ, Hsu JT. Trabecular bone structural parameters evaluated using dental cone-beam computed tomography: cellular synthetic bones. Biomedical engineering online. 2013;12:115. doi: 10.1186/1475-925X-12-115. PubMed PMID: 24207062; PubMed Central PMCID: PMC3826852.

114. Naitoh M, Aimiya H, Hirukawa A, Ariji E. Morphometric analysis of mandibular trabecular bone using cone beam computed tomography: an in vitro study. The International journal of oral \& maxillofacial implants. 2010;25(6):1093-8. PubMed PMID: 21197484.

115. Kim JE, Yi WJ, Heo MS, Lee SS, Choi SC, Huh KH. Three-dimensional evaluation of human jaw bone microarchitecture: correlation between the microarchitectural parameters of cone beam computed tomography and micro-computer tomography. Oral surgery, oral medicine, oral pathology and oral radiology. 2015;120(6):762-70. doi: 10.1016/j.0ooo.2015.08.022. PubMed PMID: 26548728.

116. Hsu JT, Wang SP, Huang HL, Chen YJ, Wu J, Tsai MT. The assessment of trabecular bone parameters and cortical bone strength: a comparison of micro-CT and dental cone-beam CT. 
Journal of biomechanics. 2013;46(15):2611-8. doi: 10.1016/j.jbiomech.2013.08.004. PubMed PMID: 24011361.

117. Monje A, Monje F, Gonzalez-Garcia R, Galindo-Moreno P, Rodriguez-Salvanes F, Wang HL. Comparison between microcomputed tomography and cone-beam computed tomography radiologic bone to assess atrophic posterior maxilla density and microarchitecture. Clinical oral implants research. 2013. doi: 10.1111/clr.12133. PubMed PMID: 23442126.

118. Ibrahim N, Parsa A, Hassan B, van der Stelt P, Aartman IH, Wismeijer D. The effect of scan parameters on cone beam $\mathrm{CT}$ trabecular bone microstructural measurements of human mandible. Dento maxillo facial radiology. 2013;42(10):20130206. PubMed PMID: 24404603.

119. Loubele M, Bogaerts R, Van Dijck E, Pauwels R, Vanheusden S, Suetens $\mathrm{P}$, et al. Comparison between effective radiation dose of CBCT and MSCT scanners for dentomaxillofacial applications. European journal of radiology. 2009;71(3):461-8. doi: 10.1016/j.ejrad.2008.06.002. PubMed PMID: 18639404.

120. Ludlow JB, Ivanovic M. Comparative dosimetry of dental CBCT devices and 64-slice CT for oral and maxillofacial radiology. Oral surgery, oral medicine, oral pathology, oral radiology, and endodontics. 2008;106(1):106-14. doi: 10.1016/j.tripleo.2008.03.018. PubMed PMID: 18504152.

121. Pauwels R, Beinsberger J, Collaert B, Theodorakou C, Rogers J, Walker A, et al. Effective dose range for dental cone beam computed tomography scanners. European journal of radiology. 2012;81(2):267-71. doi: 10.1016/j.ejrad.2010.11.028. PubMed PMID: 21196094.

122. Helmrot $E$, Thilander-Klang $A$. Methods for monitoring patient dose in dental radiology. Radiation protection dosimetry. 2010;139(1-3):303-5. doi: 10.1093/rpd/ncq095. PubMed PMID: 20223852.

123. Gonzalez-Garcia R, Monje F. The reliability of cone-beam computed tomography to assess bone density at dental implant recipient sites: a histomorphometric analysis by micro-CT. Clinical oral implants research. 2013;24(8):871-9. doi: 10.1111/j.1600-0501.2011.02390.x. PubMed PMID: 22250839.

124. Arisan V, Karabuda ZC, Avsever H, Ozdemir T. Conventional multi-slice computed tomography (CT) and cone-beam CT (CBCT) for computer-assisted implant placement. Part I: relationship of radiographic gray density and implant stability. Clinical implant dentistry and related research. 2013;15(6):893-906. doi: 10.1111/j.1708-8208.2011.00436.x. PubMed PMID: 22251553.

125. Otsu N. THRESHOLD SELECTION METHOD FROM GRAY-LEVEL HISTOGRAMS. leee Transactions on Systems Man and Cybernetics. 1979;9(1):62-6. PubMed PMID: WOS:A1979GE96000010.

126. Revol-Muller $\mathrm{C}$, Peyrin F, Carrillon $\mathrm{Y}$, Odet $\mathrm{C}$. Automated $3 \mathrm{D}$ region growing algorithm based on an assessment function. Pattern Recognition Letters. 2002;23(1-3):137-50. doi: 10.1016/s0167-8655(01)00116-7. PubMed PMID: WOS:000172398200013.

127. Petersson J, Brismar T, Smedby O. Analysis of skeletal microstructure with clinical multislice CT. In: Larsen R, Nielsen M, Sporring J, editors. Medical Image Computing and ComputerAssisted Intervention - Miccai 2006, Pt 2. Lecture Notes in Computer Science. 4191. Berlin: Springer-Verlag Berlin; 2006. p. 880-7.

128. Prendergast PJ. Finite element models in tissue mechanics and orthopaedic implant design. Clinical biomechanics. 1997;12(6):343-66. PubMed PMID: 11415744.

129. Dall'Ara E, Eastell R, Viceconti M, Pahr D, Yang L. Experimental validation of DXA-based finite element models for prediction of femoral strength. Journal of the mechanical behavior of biomedical materials. 2016;63:17-25. doi: 10.1016/j.jmbbm.2016.06.004. PubMed PMID: 27341287. 
130. Naylor KE, McCloskey EV, Eastell R, Yang L. Use of DXA-based finite element analysis of the proximal femur in a longitudinal study of hip fracture. Journal of bone and mineral research : the official journal of the American Society for Bone and Mineral Research. 2013;28(5):101421. doi: 10.1002/jbmr.1856. PubMed PMID: 23281096.

131. Imai K, Ohnishi I, Matsumoto T, Yamamoto S, Nakamura K. Assessment of vertebral fracture risk and therapeutic effects of alendronate in postmenopausal women using a quantitative computed tomography-based nonlinear finite element method. Osteoporosis international : a journal established as result of cooperation between the European Foundation for Osteoporosis and the National Osteoporosis Foundation of the USA. 2009;20(5):801-10. doi: 10.1007/s00198-008-0750-8. PubMed PMID: 18800178.

132. Carpenter RD. Finite element analysis of the hip and spine based on quantitative computed tomography. Current osteoporosis reports. 2013;11(2):156-62. doi: 10.1007/s11914-0130141-8. PubMed PMID: 23504495.

133. Brekelmans WA, Poort HW, Slooff TJ. A new method to analyse the mechanical behaviour of skeletal parts. Acta Orthop Scand. 1972;43(5):301-17. PubMed PMID: 4651051.

134. Zysset PK, Guo XE, Hoffler CE, Moore KE, Goldstein SA. Elastic modulus and hardness of cortical and trabecular bone lamellae measured by nanoindentation in the human femur. Journal of biomechanics. 1999;32(10):1005-12. PubMed PMID: 10476838.

135. Wolfram U, Wilke HJ, Zysset PK. Valid micro finite element models of vertebral trabecular bone can be obtained using tissue properties measured with nanoindentation under wet conditions. Journal of biomechanics. 2010;43(9):1731-7. doi: 10.1016/j.jbiomech.2010.02.026. PubMed PMID: 20206932.

136. van Rietbergen B, Ito K. A survey of micro-finite element analysis for clinical assessment of bone strength: the first decade. Journal of biomechanics. 2015;48(5):832-41. doi: 10.1016/j.jbiomech.2014.12.024. PubMed PMID: 25553670.

137. Cheung AM, Adachi JD, Hanley DA, Kendler DL, Davison KS, Josse R, et al. High-resolution peripheral quantitative computed tomography for the assessment of bone strength and structure: a review by the Canadian Bone Strength Working Group. Current osteoporosis reports. 2013;11(2):136-46. doi: 10.1007/s11914-013-0140-9. PubMed PMID: 23525967; PubMed Central PMCID: PMCPMC3641288.

138. Macneil JA, Boyd SK. Bone strength at the distal radius can be estimated from high-resolution peripheral quantitative computed tomography and the finite element method. Bone. 2008;42(6):1203-13. doi: 10.1016/j.bone.2008.01.017. PubMed PMID: 18358799.

139. MacNeil JA, Boyd SK. Improved reproducibility of high-resolution peripheral quantitative computed tomography for measurement of bone quality. Medical engineering \& physics. 2008;30(6):792-9. doi: 10.1016/j.medengphy.2007.11.003. PubMed PMID: 18164643.

140. Christen D, Melton LJ, 3rd, Zwahlen A, Amin S, Khosla S, Muller R. Improved fracture risk assessment based on nonlinear micro-finite element simulations from HRpQCT images at the distal radius. Journal of bone and mineral research : the official journal of the American Society for Bone and Mineral Research. 2013;28(12):2601-8. doi: 10.1002/jbmr.1996. PubMed PMID: 23703921; PubMed Central PMCID: PMC3818502.

141. Moreno R, Borga M, Klintström E, Brismar T, Smedby Ö. Correlations between fabric tensors computed on cone beam and microcomputed tomography images. 2013.

142. Moreno R, Borga $M$, Smedby O. Generalizing the mean intercept length tensor for gray-level images. Medical physics. 2012;39(7):4599-612. doi: 10.1118/1.4730502. PubMed PMID: 22830791. 
143. Goulet RW, Goldstein SA, Ciarelli MJ, Kuhn JL, Brown MB, Feldkamp LA. The relationship between the structural and orthogonal compressive properties of trabecular bone. Journal of biomechanics. 1994;27(4):375-89. PubMed PMID: 8188719.

144. Faulkner KG, Cann CE, Hasegawa BH. Effect of bone distribution on vertebral strength: assessment with patient-specific nonlinear finite element analysis. Radiology. 1991;179(3):669-74. doi: 10.1148/radiology.179.3.2027972. PubMed PMID: 2027972.

145. Kontulainen $\mathrm{S}$, Sievanen $\mathrm{H}$, Kannus $\mathrm{P}$, Pasanen $\mathrm{M}$, Vuori I. Effect of long-term impact-loading on mass, size, and estimated strength of humerus and radius of female racquet-sports players: a peripheral quantitative computed tomography study between young and old starters and controls. Journal of bone and mineral research : the official journal of the American Society for Bone and Mineral Research. 2002;17(12):2281-9. doi: 10.1359/jbmr.2002.17.12.2281. PubMed PMID: 12469923.

146. Aaron JE, Shore PA, Shore RC, Beneton M, Kanis JA. Trabecular architecture in women and men of similar bone mass with and without vertebral fracture: II. Three-dimensional histology. Bone. 2000;27(2):277-82. doi: 10.1016/s8756-3282(00)00328-8. PubMed PMID: WOS:000088489000014.

147. Legrand E AM, Guggenbuhl P, Levasseur R, Chalés G, Baslé, Chappard D. Trabecular bone microarchitecture is related to the number of risk factors and etiology in osteoporotic men. Micros Res Tech. 2007;70(11):952-9.

148. Legrand E, Chappard D, Pascaretti C, Duquenne M, Krebs S, Rohmer V, et al. Trabecular bone microarchitecture, bone mineral density, and vertebral fractures in male osteoporosis. J Bone Miner Res. 2000;15(1):13-9. doi: 10.1359/jbmr.2000.15.1.13. PubMed PMID: WOS:000084420800004.

149. Liu-Ambrose T, Khan KM, Eng JJ, Janssen PA, Lord SR, McKay HA. Resistance and agility training reduce fall risk in women aged 75 to 85 with low bone mass: a 6-month randomized, controlled trial. Journal of the American Geriatrics Society. 2004;52(5):657-65. doi: 10.1111/j.1532-5415.2004.52200.x. PubMed PMID: 15086643; PubMed Central PMCID: PMCPMC3344816.

150. Jara $\mathrm{H}$, Wehrli FW, Chung $\mathrm{H}$, Ford JC. High-resolution variable flip angle 3D MR imaging of trabecular microstructure in vivo. Magnetic resonance in medicine : official journal of the Society of Magnetic Resonance in Medicine / Society of Magnetic Resonance in Medicine. 1993;29(4):528-39. PubMed PMID: 8464369.

151. Phan CM, Matsuura M, Bauer JS, Dunn TC, Newitt D, Lochmueller EM, et al. Trabecular bone structure of the calcaneus: comparison of MR imaging at 3.0 and $1.5 \mathrm{~T}$ with micro-CT as the standard of reference. Radiology. 2006;239(2):488-96. doi: 10.1148/radiol.2392050574. PubMed PMID: 16569786.

152. Link TM, Majumdar S, Augat P, Lin JC, Newitt D, Lu Y, et al. In vivo high resolution MRI of the calcaneus: differences in trabecular structure in osteoporosis patients. Journal of bone and mineral research : the official journal of the American Society for Bone and Mineral Research. 1998;13(7):1175-82. doi: 10.1359/jbmr.1998.13.7.1175. PubMed PMID: 9661082.

153. Chang G, Honig S, Liu Y, Chen C, Chu KK, Rajapakse CS, et al. 7 Tesla MRI of bone microarchitecture discriminates between women without and with fragility fractures who do not differ by bone mineral density. J Bone Miner Metab. 2015;33(3):285-93. doi: 10.1007/s00774-014-0588-4. PubMed PMID: 24752823; PubMed Central PMCID: PMCPMC4363287.

154. Leitz W AA. Patientdoser från röntgenundersökningar i Sverige 
- utveckling från 2005 till 2008. Swedish Radiation Safety Authority. 2010.

155. Link TM, Vieth V, Stehling C, Lotter A, Beer A, Newitt D, et al. High-resolution MRI vs multislice spiral CT: which technique depicts the trabecular bone structure best? Eur Radiol. 2003;13(4):663-71. doi: 10.1007/s00330-002-1695-5. PubMed PMID: 12664101.

156. Patel PV, Prevrhal S, Bauer JS, Phan C, Eckstein F, Lochmuller EM, et al. Trabecular bone structure obtained from multislice spiral computed tomography of the calcaneus predicts osteoporotic vertebral deformities. Journal of computer assisted tomography. 2005;29(2):24653. PubMed PMID: 15772547.

157. Bauer JS, Kohlmann S, Eckstein F, Mueller D, Lochmuller EM, Link T. Structural analysis of trabecular bone of the proximal femur using multislice computed tomography: A comparison with dual $\mathrm{x}$-ray absorptiometry for predicting biomechanical strength in vitro. Calcified tissue international. 2006;78(2):78-89. doi: 10.1007/s00223-005-0070-3. PubMed PMID: WOS:000235307100003.

158. Brembeck $\mathrm{P}$, Lorentzon $\mathrm{M}$, Ohlsson $\mathrm{C}$, Winkvist A, Augustin H. Changes in cortical volumetric bone mineral density and thickness, and trabecular thickness in lactating women postpartum. The Journal of clinical endocrinology and metabolism. 2015;100(2):535-43. doi: 10.1210/jc.2014-2825. PubMed PMID: 25387262.

159. Burghardt AJ, Kazakia GJ, Ramachandran S, Link TM, Majumdar S. Age- and gender-related differences in the geometric properties and biomechanical significance of intracortical porosity in the distal radius and tibia. Journal of bone and mineral research : the official journal of the American Society for Bone and Mineral Research. 2010;25(5):983-93. doi: 10.1359/jbmr.091104. PubMed PMID: 19888900; PubMed Central PMCID: PMCPMC3153365.

160. Amstrup AK, Jakobsen NFB, Moser E, Sikjaer T, Mosekilde L, Rejnmark L. Association between bone indices assessed by DXA, HR-pQCT and QCT scans in post-menopausal women. Journal of Bone and Mineral Metabolism. 2016;34(6):638-45. doi: 10.1007/s00774-015-0708-9.

161. Manske SL, Zhu Y, Sandino C, Boyd SK. Human trabecular bone microarchitecture can be assessed independently of density with second generation HR-pQCT. Bone. 2015;79:213-21. doi: 10.1016/j.bone.2015.06.006. PubMed PMID: 26079995.

162. Engelke K, Stampa B, Timm W, Dardzinski B, de Papp AE, Genant HK, et al. Short-term in vivo precision of BMD and parameters of trabecular architecture at the distal forearm and tibia. Osteoporosis international : a journal established as result of cooperation between the European Foundation for Osteoporosis and the National Osteoporosis Foundation of the USA. 2012;23(8):2151-8. doi: 10.1007/s00198-011-1829-1. PubMed PMID: 22143491.

163. Agarwal S, Rosete F, Zhang C, McMahon DJ, Guo XE, Shane E, et al. In vivo assessment of bone structure and estimated bone strength by first- and second-generation HR-pQCT.

Osteoporosis international : a journal established as result of cooperation between the European Foundation for Osteoporosis and the National Osteoporosis Foundation of the USA. 2016;27(10):2955-66. doi: 10.1007/s00198-016-3621-8. PubMed PMID: 27155883.

164. Pittayapat P, Willems G, Alqerban A, Coucke W, Ribeiro-Rotta RF, Souza PC, et al. Agreement between cone beam computed tomography images and panoramic radiographs for initial orthodontic evaluation. Oral surgery, oral medicine, oral pathology and oral radiology. 2014;117(1):111-9. doi: 10.1016/j.oooo.2013.10.016. PubMed PMID: 24332335.

165. Liang X, Jacobs R, Hassan B, Li L, Pauwels R, Corpas L, et al. A comparative evaluation of Cone Beam Computed Tomography (CBCT) and Multi-Slice CT (MSCT) Part I. On subjective image quality. European journal of radiology. 2010;75(2):265-9. doi: 10.1016/j.ejrad.2009.03.042. PubMed PMID: 19410409. 
166. Xu J, Reh DD, Carey JP, Mahesh M, Siewerdsen JH. Technical assessment of a cone-beam CT scanner for otolaryngology imaging: image quality, dose, and technique protocols. Medical physics. 2012;39(8):4932-42. doi: 10.1118/1.4736805. PubMed PMID: 22894419.

167. Koivisto J, Kiljunen T, Kadesjo N, Shi XQ, Wolff J. Effective radiation dose of a MSCT, two CBCT and one conventional radiography device in the ankle region. J Foot Ankle Res. 2015;8:8. doi: 10.1186/s13047-015-0067-8. PubMed PMID: 25788986; PubMed Central PMCID: PMCPMC4363062.

168. Koivisto J, Wolff J, Jarnstedt J, Dastidar P, Kortesniemi M. Assessment of the effective dose in supine, prone, and oblique positions in the maxillofacial region using a novel combined extremity and maxillofacial cone beam computed tomography scanner. Oral surgery, oral medicine, oral pathology and oral radiology. 2014;118(3):355-62. doi: 10.1016/j.oooo.2014.05.016. PubMed PMID: 25151590.

169. Ibrahim N, Parsa A, Hassan B, van der Stelt P, Aartman IH, Wismeijer D. Accuracy of trabecular bone microstructural measurement at planned dental implant sites using cone-beam CT datasets. Clinical oral implants research. 2014;25(8):941-5. doi: 10.1111/clr.12163. PubMed PMID: 23581278.

170. de Charry C, Boutroy S, Ellouz R, Duboeuf F, Chapurlat R, Follet H, et al. Clinical cone beam computed tomography compared to high-resolution peripheral computed tomography in the assessment of distal radius bone. Osteoporosis international : a journal established as result of cooperation between the European Foundation for Osteoporosis and the National Osteoporosis Foundation of the USA. 2016;27(10):3073-82. doi: 10.1007/s00198-016-3609-4. PubMed PMID: 27121345.

171. Yeni YN, Brown CU, Wang Z, Norman TL. The influence of bone morphology on fracture toughness of the human femur and tibia. Bone. 1997;21(5):453-9. PubMed PMID: 9356740.

172. Nishiyama KK, Macdonald HM, Buie HR, Hanley DA, Boyd SK. Postmenopausal women with osteopenia have higher cortical porosity and thinner cortices at the distal radius and tibia than women with normal aBMD: an in vivo HR-pQCT study. Journal of bone and mineral research : the official journal of the American Society for Bone and Mineral Research. 2010;25(4):882-90. doi: 10.1359/jbmr.091020. PubMed PMID: 19839766.

173. Burghardt AJ, Buie HR, Laib A, Majumdar S, Boyd SK. Reproducibility of direct quantitative measures of cortical bone microarchitecture of the distal radius and tibia by HR-pQCT. Bone. 2010;47(3):519-28. doi: 10.1016/j.bone.2010.05.034. PubMed PMID: 20561906; PubMed Central PMCID: PMCPMC2926164.

174. Sundh D, Nilsson AG, Nilsson M, Johansson L, Mellstrom D, Lorentzon M. Increased cortical porosity in women with hip fracture. Journal of internal medicine. 2017;281(5):496-506. doi: 10.1111/joim.12587. PubMed PMID: 28097725.

175. Parkinson IH, Badiei A, Fazzalari NL. Variation in segmentation of bone from micro-CT imaging: implications for quantitative morphometric analysis. Australasian Physical \& Engineering Sciences in Medicine. 2008;31(2):160-4. PubMed PMID: WOS:000260466800011.

176. Moreno R, Borga M, Smedby Ö, editors. Estimation of trabecular thickness in gray-scale images through granulometric analysis. SPIE Medical Imaging; 2012: International Society for Optics and Photonics.

177. Nakashima T, Hayashi M, Fukunaga $T$, Kurata K, Oh-Hora M, Feng JQ, et al. Evidence for osteocyte regulation of bone homeostasis through RANKL expression. Nat Med. 2011;17(10):1231-4. doi: 10.1038/nm.2452. PubMed PMID: 21909105. 
178. Güldner C, Diogo I, Bernd E, Dräger S, Mandapathil M, Teymoortash A, et al. Visualization of anatomy in normal and pathologic middle ears by cone beam CT. European Archives of OtoRhino-Laryngology. 2017;274(2):737-42. doi: 10.1007/s00405-016-4345-2.

179. Lindh C, Horner K, Jonasson G, Olsson P, Rohlin M, Jacobs R, et al. The use of visual assessment of dental radiographs for identifying women at risk of having osteoporosis: the OSTEODENT project. Oral surgery, oral medicine, oral pathology, oral radiology, and endodontics. 2008;106(2):285-93. doi: 10.1016/j.tripleo.2007.09.008. PubMed PMID: 18299223.

180. Jonasson G, Sundh V, Hakeberg M, Hassani-Nejad A, Lissner L, Ahlqwist M. Mandibular bone changes in 24 years and skeletal fracture prediction. Clinical oral investigations. 2013;17(2):565-72. doi: 10.1007/s00784-012-0745-x. PubMed PMID: 22547324.

181. Devlin H, Allen PD, Graham J, Jacobs R, Karayianni K, Lindh C, et al. Automated osteoporosis risk assessment by dentists: a new pathway to diagnosis. Bone. 2007;40(4):835-42. doi: 10.1016/j.bone.2006.10.024. PubMed PMID: 17188590.

182. Sundh V, Hange D, Ahlqwist M, Hakeberg M, Lissner L, Jonasson G. FRAX and mandibular sparse trabeculation as fracture predictors: a longitudinal study from 1980 to 2002. European journal of oral sciences. 2017;125(2):135-40. doi: 10.1111/eos.12341. PubMed PMID: 28263008. 


\section{Papers}

The papers associated with this thesis have been removed for copyright reasons. For more details about these see:

http:// urn.kb.se/ resolve?urn=urn:nbn:se:liu:diva-142066 